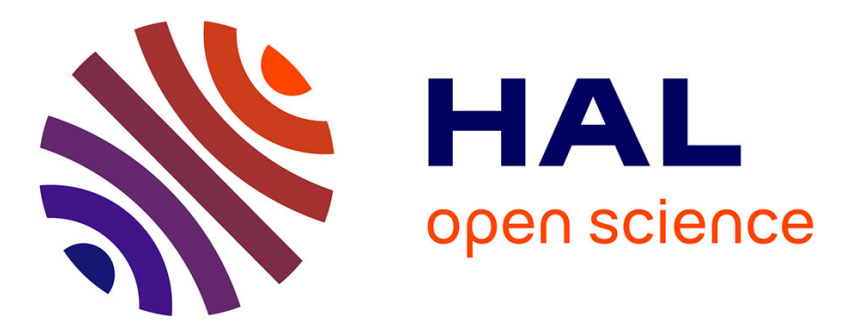

\title{
Uncertainties in Shoreline Projections to 2100 at Truc Vert beach (France): Role of Sea-Level Rise and Equilibrium Model Assumptions
}

Maurizio d'Anna, Bruno Castelle, Déborah Idier, Jérémy Rohmer, Gonéri Le Cozannet, Rémi Thiéblemont, Lucy Bricheno

\section{To cite this version:}

Maurizio d'Anna, Bruno Castelle, Déborah Idier, Jérémy Rohmer, Gonéri Le Cozannet, et al.. Uncertainties in Shoreline Projections to 2100 at Truc Vert beach (France): Role of Sea-Level Rise and Equilibrium Model Assumptions. 2021. hal-03338001

\section{HAL Id: hal-03338001 https://hal.science/hal-03338001}

Preprint submitted on 8 Sep 2021

HAL is a multi-disciplinary open access archive for the deposit and dissemination of scientific research documents, whether they are published or not. The documents may come from teaching and research institutions in France or abroad, or from public or private research centers.
L'archive ouverte pluridisciplinaire $\mathbf{H A L}$, est destinée au dépôt et à la diffusion de documents scientifiques de niveau recherche, publiés ou non, émanant des établissements d'enseignement et de recherche français ou étrangers, des laboratoires publics ou privés. 
10 Corresponding author: Maurizio D’Anna (m.danna@brgm.fr)

11 *BRGM, 3 Avenue Guillemin, 4060, Orléans, France. and L. Bricheno ${ }^{3}$

${ }^{1}$ BRGM, French Geological Survey, Orléans, France.

${ }^{2}$ Université de Bordeaux, UMR EPOC, CNRS, Pessac, France.

${ }^{3}$ National Oceanography Center, Liverpool, UK.

9

\title{
Uncertainties in Shoreline Projections to 2100 at Truc Vert beach (France): Role of Sea-Level Rise and Equilibrium Model Assumptions
}

\author{
M. D’Anna ${ }^{1,2 *}$, B. Castelle ${ }^{2}$, D. Idier ${ }^{1}$, J. Rohmer ${ }^{1}$, G. Le Cozannet ${ }^{1}$, R. Thieblemont ${ }^{1}$,
}

12

\section{Key Points:}

- Ensemble-based simulations of future shoreline evolution to 2100, including sea-level rise driven erosion, are performed and analysed

- Future shoreline projections uncertainties are initially controlled by modelling assumptions and after 2060 by sea-level rise uncertainties

- The choice of wave-driven equilibrium modelling approach and incident wave chronology are critical to short/mid-term shoreline projections 


\section{Abstract}

Sandy shorelines morphodynamics responds to a myriad of processes interacting at different spatial and temporal scales, making shoreline predictions challenging. Shoreline modelling inherits uncertainties from the primary driver boundary conditions (e.g. sea-level rise and wave forcing) as well as uncertainties related to model assumptions and/or misspecifications of the physics. This study presents an analysis of the uncertainties associated with future shoreline evolution at the cross-shore transport dominated sandy beach of Truc Vert (France) over the $21^{\text {st }}$ century. We explicitly resolve wave-driven shoreline change using two different equilibrium modelling approaches to provide new insight into the contributions of sea-level rise, and free model parameters uncertainties on future shoreline change in the frame of climate change. Based on a Global Sensitivity Analysis, shoreline response during the first half of the century is found to be mainly sensitive to the equilibrium model parameters, with the influence of sea-level rise emerging in the second half of the century ( 2050 or later), under several simulated scenarios. The results reveal that the seasonal and interannual variability of the predicted shoreline position is sensitive to the choice of the wave-driven equilibrium-based model. Finally, we discuss the importance of the chronology of wave events in future shoreline change, calling for more continuous wave projection time series to further address uncertainties in future wave conditions. Our contribution demonstrates that unmitigated climate change can result in shoreline retreat of several tens of meters by 2100 , even for sectors that have been stable or slightly accreting over the last century.

\section{Introduction}

Ongoing climate change is one of the largest concerns of our time, and its largest impacts on the world's environment are yet to come. Global mean sea-level rise is accelerating since 1870, and is expected to continue rising over the $21^{\text {st }}$ century, although acceleration may be avoided if the Paris Agreement 'below $2^{\circ} \mathrm{C}$ climate warming' target is met (Church et al., 2013; Oppenheimer et al., 2019). In addition, global wave power is adapting to the sea surface temperature since the late 1940's (Reguero et al., 2019), and is expected to change along with storminess by 2100 (Morim et al., 2020). 
Sandy beaches provide precious natural, structural and social-economical resources to coastal communities (Ghermandi \& Nunes, 2013; Poumadère et al., 2015), and constitute about one third of the ice-free coasts worldwide (Luijendijk et al., 2018). Open sandy beaches constantly evolve in response to multiple environmental drivers occurring on different time scales, making sandy shoreline dynamics strongly sensitive to sea-level rise and wave climate change (Ranasinghe, 2016, 2020). Meanwhile, the expected growth of population density in low-lying coastal areas during the twenty-first century (Merkens et al., 2016; Neumann et al., 2015) increases the need for efficient adaptation plans of coastal communities (Oppenheimer et al., 2019).

The spatial heterogeneity of sea-level rise (SLR), wave-climate change, time scales of adaptation, and vulnerability of coastal communities raises the need for shoreline projections with their related uncertainties that provide full support to risk-informed decision making process (Hinkel et al., 2019; Losada et al., 2019; Toimil et al., 2018, 2020; Wainwright et al., 2015). However, limits in our understanding and modelling capacity of the primary processes driving shoreline change, together with the uncertainties associated to the future climate (e.g. carbon emission scenario, SLR, storminess, etc.), undermine the confidence in future shoreline estimates proportionally to the time scale of application (Ranasinghe, 2020; Toimil et al., 2020). Many studies focused on the effects of SLR uncertainties (Athanasiou et al., 2020; Le Cozannet et al., 2016, 2019; Thiéblemont et al., 2021; Vousdoukas et al., 2020) and changes in storminess based on data extrapolation and/or empirical models (Allenbach et al., 2015; Casas-Prat et al., 2016; Toimil et al., 2017; Vousdoukas et al., 2020) on future shoreline uncertainties. However, these studies do not explicitly resolve wave-driven shoreline change, and it is advocated that new methods have to be developed to predict the impacts of SLR on the coast (Cooper et al., 2020). Short- and long-term variability in wave energy, as well as the chronology of storm events, can strongly affect future shoreline 
patterns (Besio et al., 2017; Cagigal et al., 2020; Coco et al., 2014; Dissanayake et al., 2015; Vitousek et al., 2021). Recently, Cagigal et al. (2020) developed and used a stochastic climatebased wave emulator to generate ensembles of wave time series at several beaches, and addressed shoreline response to different wave chronologies. Based on the same emulator, Vitousek et al. (2021) analytically investigated the uncertainties in shoreline predictions associated to the inherent variability of the wave climate in the context of equilibrium shoreline modelling. Kroon et al. (2020) showed the significant effects of wave-climate variability and model uncertainty on the short-term (1 year) probabilistic assessment of coastline change at the Sand Engine (Netherlands). The authors used a one-line model, i.e. resolving wave-driven longshore sediment transport gradients and resulting shoreline evolution, as this stretch of coast is longshore transport dominated.

Currently, there are no studies addressing the time evolution of the effects that uncertainties in future SLR and model parameters have on shoreline projections to the end of the $21^{\text {st }}$ century while explicitly resolving wave-driven shoreline response. The recent development of equilibrium shoreline models opened the way to skilful simulation of wave-driven shoreline response on crossshore transport dominated sites, which are ubiquitous worldwide, on time scales from hours (storm events) to decades, with low computational cost (Antolínez et al., 2019; Davidson et al., 2013; Lemos et al., 2018; Robinet et al., 2018; Splinter et al., 2014a; Vitousek et al., 2017; Yates et al., 2009). Equilibrium shoreline models are based on the principle that the shoreline dynamically moves towards a time-varying equilibrium condition (Wright \& Short, 1984), which can be expressed as a function of the current shoreline position (Yates et al., 2009) or antecedent wave conditions (Davidson et al. 2013). While the two latter equilibrium formulations show similar skill against shoreline observations on a multi-year timescale (Castelle et al., 2014; Montaño et al., 
2020), the accuracy of one approach over the other in different wave forcing scenarios is unclear, particularly on long timescales (multi-decadal). In addition, in this type of models, sediment transport processes are described by semi-empirical relationships that require site-specific calibration against observed shoreline data, introducing further uncertainty (D'Anna et al., 2020; Splinter et al., 2013). Implementations of cross-shore equilibrium models into probabilistic frameworks recently showed that uncertainties in the calibration of model free parameters (D’Anna et al., 2020) and in future wave conditions (Vitousek et al., 2021) have a significant impact on model predictions. In addition, recent studies found an inherent connection between the seasonality of wave climate and shoreline model parameters that defines the frequency of shoreline response, for several beaches along the Australian coast (Ibaceta et al., 2020; Splinter et al., 2017).

SLR-driven shoreline retreat is often estimated using the Bruun (1962) model. This model relates the rate of shoreline erosion to the SLR rate and the average slope of the active beach profile, defined between the seaward and landward limits of cross-shore sediment exchange. The seaward limit of the active beach profile is commonly identified by the depth of closure (Hallermaier, 1978). As local scale bathymetric surveys are scarce and the estimation of the depth of closure is essentially empirical, the active beach profile slope is typically associated with large uncertainties (Nicholls, 1998; Ranasinghe et al., 2012).

In this work, we aim at deepening our understanding in the role and impact of different uncertainties in shoreline projections. We perform a Global Sensitivity Analysis (GSA) (Saltelli et al., 2008) to unravel the respective contributions of SLR, depth of closure, and shoreline model free parameters uncertainties. The framework is applied to the cross-shore dominated Truc Vert beach (SW France) using two different wave-driven shoreline models, the Bruun model, and stateof-the-art SLR and wave projections for two future Representative Concentration Pathways (RCP) 
118 scenarios. The likely range provided along with median SLR estimates in IPCC reports does not

119 cover the full uncertainty range of mean sea level projections. Hence, there remains a probability

120 of up to $33 \%$ that sea-level rise exceeds the likely range. Therefore, we also assess shoreline

121 projections in the deterministic high-end SLR scenario, which remains unlikely but plausible and

122 is associated with large impacts (Stammer et al 2019). The remainder of this paper includes: an

123 outline of Truc Vert beach, the data, the shoreline models, and the method (Section 2); a

124 description of the GSA input variables' probability distributions and the numerical modelling setup

125 (Section 3); and the presentation of the results (Section 4). Discussion and conclusions are 126 provided in Section 5 and 6, respectively. 


\section{Study site, data and method}

\subsection{Truc Vert beach}

Truc Vert is a meso-macrotidal wave dominated sandy beach located in the south of the Gironde coast, southwest France, which extends roughly $100 \mathrm{~km}$ between the Gironde river estuary and the south of the Arcachon basin (Figure 1a,b). Truc Vert is backed by a high ( 20 m) and wide ( 250 m) coastal dune system (Robin et al., 2021). The wave climate is characterized by strong seasonal energy fluctuations, and strong interannual winter energy variability (Castelle et al., 2018a; Charles et al., 2012; Robinet et al., 2016), the latter associated to large-scale climate patterns of atmospheric variability in the northeast Atlantic region (Castelle et al., 2017). Monthly-averaged significant wave height ranges from $1.1 \mathrm{~m}$ in August with dominant W-NW direction to $2.4 \mathrm{~m}$ in January with dominant W direction. Truc Vert beach has been intensively monitored since 2003 with monthly to bi-monthly topographic DGPS surveys, with additional daily topographic surveys and high-resolution bathymetric surveys collected during the ECORS'08 field campaign (Parisot et al., 2009), see Castelle et al. (2020) for detailed description of the datasets. Since 2017, highresolution digital elevation model covering $4 \mathrm{~km}$ of beach-dune are also derived seasonally from photogrammetry of UAV images (Laporte-Fauret et al., 2019).

The beach morphology is highly dynamic and responds primarily to cross-shore processes driven by the temporal variability of the incident wave climate (Castelle et al., 2014; Robinet et al., 2016, 2018). Overall, this segment of coastline has been observed to be reasonably stable over the past decades (Castelle et al., 2018b), although the interannual distribution of winter wave energy may result in episodic severe beach and dune erosion (Castelle et al., 2015; Masselink et al., 2016). 

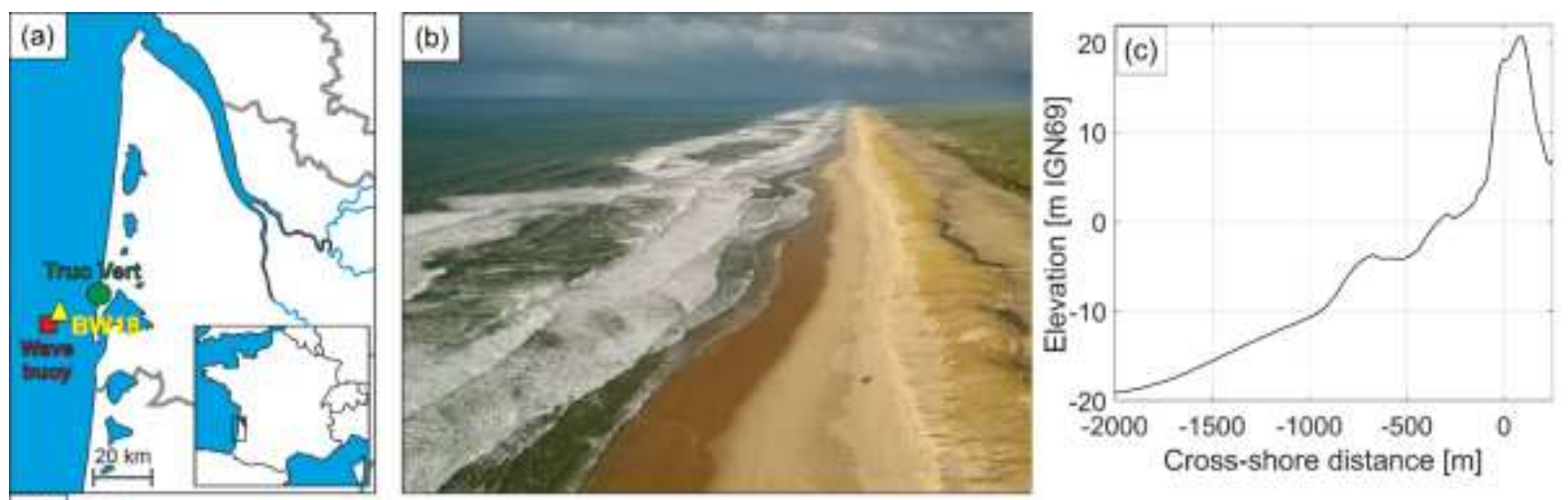

(d)

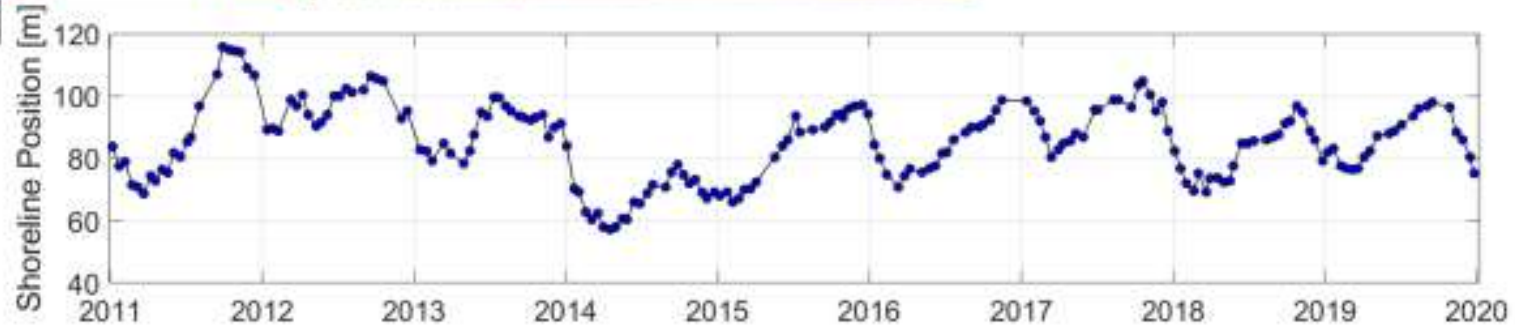

150 
163 Historical wave data $\left(H_{s}, T_{p}\right.$, and $\left.D_{m}\right)$, from January 1994 to January 2020, was extracted from the 164 NORGAS-UG regional hindcast model (Michaud et al., 2016) at the grid point co-located with the in situ CANDHIS wave buoy (4439'9”' N; 1²6’48” W) moored in $~ 50$ m depth offshore of Truc Vert beach (Figure 1a). The NORGAS-UG model covers the French Atlantic coastal area using an unstructured mesh grid with resolution of $10 \mathrm{~km}$ offshore, increasing to $200 \mathrm{~m}$ nearshore. The wave model was validated against several French and international wave buoy data, and showed 0.96-0.99 correlations coefficients, 0.15-0.21 m RMSE, and -0.02 to $0.04 \mathrm{~m}$ bias (Michaud et al., 2016). The hindcasted wave time series (1994-2020) shows the typical seasonal and interannual modulation of the incident wave climate at Truc Vert beach (Figure 2a).

2.2.2 Future wave climate (2020 - 2100)

Wave-driven shoreline change at cross-shore transport dominated sites is controlled by the variability in incident wave energy including temporal clustering and chronology of storm wave events (Splinter et al., 2014b; Dissanayake et al., 2015; Angnuureng et al., 2017). Thus, the assessment of future shoreline evolution at Truc Vert requires a continuous wave time series with high resolution (e.g. few hours). Bricheno and Wolf (2018) (hereafter BW18) provide state-of-theart wave projections throughout the $21^{\text {st }}$ century in the Northeast Atlantic region for the RCP8.5 and RCP4.5 scenarios. As part of the Coordinated Ocean Wave Climate Project (COWCLIP), BW18 wave data belong to an ensemble of global and regional wave climate projections, forced with several Global Climate Models and using different wave models. Within COWCLIP, changes were found to be robust in the North Atlantic region, suggesting a slight decrease of annual mean $H_{s}$ and a clockwise rotation of waves off the Aquitanian coast that is more pronounced for high climate forcing (Morim et al., 2019). However, amongst the COWCLIP ensemble, to our knowledge, only BW18 produced uninterrupted time series of wave data with sufficient spatial 
resolution to properly reproduce the wave climate offshore our study site. The continuous hourly time series of wave conditions was produced by BW18 using a dynamical downscaling approach and a nested setup of the WaveWatchIII® spectral wave model (Tolman, 2009). The wave model covers the Northwest European coastal area with a grid resolution of $0.083^{\circ}(<9 \mathrm{~km})$ and was forced with the downscaled EC-Earth global climate model (Hazeleger et al., 2012). For both RCP scenarios, BW18 model is run from 2006 to 2100 in a regional atmospheric model configuration $\left(\sim 0.11^{\circ}\right.$ resolution $)$, in the context of the EURO-CORDEX project. BW18 also provide the results of a historic model run, forced with the EC-Earth model climate, for the period 1970-2004. Such simulation is needed to estimate relative change between past and future wave climate or for the correction of the potential biases between the modelling results and reference wave data (e.g. wave buoy data or modelled wave hindcast), which result from climate models bias (see e.g. Charles et al., 2012). From the BW18 modelling, we extracted wave data $\left(H_{s}, T_{p}\right.$, and $\left.D_{m}\right)$ over $2020-2100$ (for shoreline projections) from the nearest grid point to the CANDHIS wave buoy ( $3 \mathrm{~km}$ NorthEast; Figure 1a), in $~ 50 \mathrm{~m}$ depth, for both RCP8.5 and RCP4.5 scenarios. To reduce the bias in modelled future waves, we analysed the seasonal quantiles of the 1994-2004 portion of BW18 historic wave time series (extracted at the same location as the 2020-2100 wave data) and the seasonal quantiles of the NORGAS-UG hindcast, and set-up a seasonal quantile-quantile correction that we applied to the 2020-2100 wave dataset (details in Text S1 of Supporting Information). The corrected BW18 wave time series for RCP8.5 and RCP4.5 scenarios are shown in Figure $2 \mathrm{~b}$ and Figure 2c, respectively. Hereon, we refer to BW18 as the corrected wave time series. 


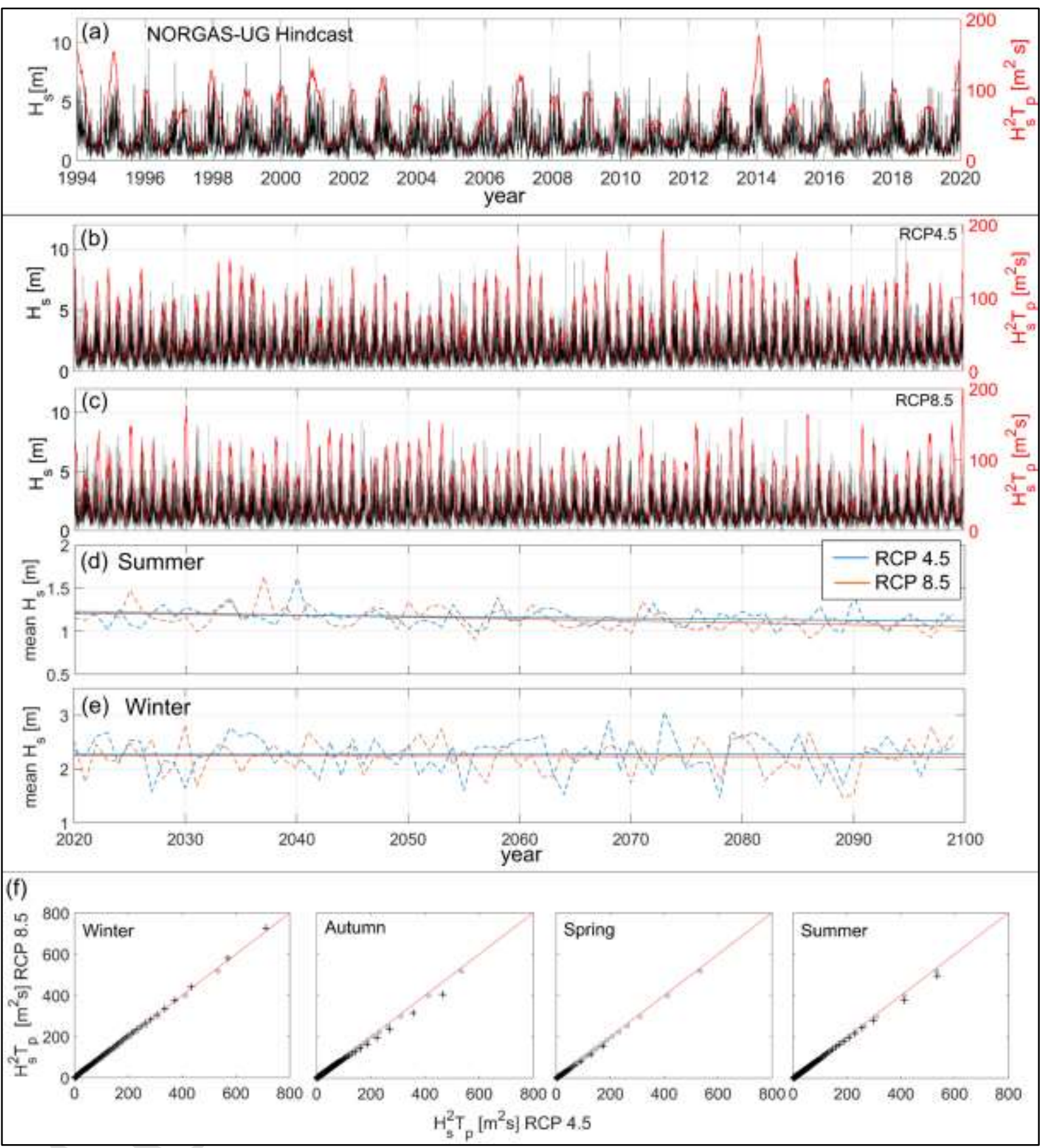

Figure 2 Wave data offshore of Truc Vert, including: time series of $H_{s}$ (black lines) and 3-month averaged $H_{s}{ }^{2} T_{p}$ (red lines) for (a) the 1994-2020 wave hindcast from NORGAS-UG model

210 (44³9'9” N; -1 1²6’48” W), and (b) RCP8.5 and (c) RCP4.5 scenarios corrected 2020-2100

211 Bricheno and Wolf (2018) wave projections; linear trends (solid lines) of annual (d) summer and 212 (e) winter mean $H_{s}$ (dashed lines) of 2020-2100 corrected Bricheno and Wolf (2018) wave 213 projections, for RCP4.5 (blue) and RCP8.5 (orange) scenarios. For RCP8.5 (RCP4.5), the trend of 
214 summer and winter mean $H_{s}$ are $-2 \mathrm{~mm} /$ year $(-1 \mathrm{~mm} /$ year) and $-0.05 \mathrm{~mm} / \mathrm{year}(-0.05 \mathrm{~mm} /$ year).

215 These trends were tested to be statistically significant (more than $99 \%$ significance) using 216 Student's t-tests. (f) Quantile-quantile comparison between RCP4.5 and RCP8.5's 3-month 217 average of $H_{s}^{2} T_{p}$ projections for the four seasons (black crosses) and for the full datasets (grey 218 circles).

Here, we adopted $H_{s}^{2} T_{p}\left(\mathrm{~m}^{2} \mathrm{~s}\right)$ as a representative variable for deep-water wave energy. The RCP8.5 and 4.5 2020-2100 wave series show a strong interannual modulation of incident wave energy, which is in line with current wave climate characteristics offshore of Truc Vert. Both scenarios of the BW18 wave projections show several peaks of the 3-month average $H_{s}{ }^{2} T_{p}$ that are comparable to the 2013-2014 outstanding high-energy winter $\left(H_{s}^{2} T_{p}=178 \mathrm{~m}^{2} \mathrm{~s}\right)$ experienced at Truc Vert (Figure 2a-c). For the RCP8.5 (RCP4.5) scenario, the projected 3-month average $H_{s}{ }^{2} T_{p}$ reaches at least $90 \%$ of the 2013-2014 peak in 2030, 2080, 2086, and $2099(2060,2068,2073$ and 2085) (Figure 2b,c). While characterized by similar integrated intensity, these winters are preceded by different multi-annual energy trends, with the RCP8.5 (RCP4.5) 2080, 2086 and 2099 (2060 and 2068) winters following a positive trend of wave energy (similarly to the 2013-2014 winter), and the 2030 (2060 and 2068) winter following a negative trend of winter energy. Although in both RCP scenarios the incident wave energy fluctuates with a similar interannual period with nearly the same average $H_{s}^{2} T_{p}\left(52\right.$ and $54 \mathrm{~m}^{2} \mathrm{~s}$ for RCP8.5 and RCP4.5, respectively), the RCP4.5 scenario associates slightly higher energy during Autumn, Summer and Spring (Figure 2f). The 2020-2100 summer mean wave height $\left({\overline{H_{s}}}_{\text {summer }}\right)$ fluctuates between $0.9 \mathrm{~m}$ and $1.7 \mathrm{~m}$, with a statistically significant decrease of $2 \mathrm{~mm} /$ year (1 mm/year) rates for the RCP8.5 (RCP4.5) (Figure 2d). Future winter mean wave height $\left({\overline{H_{s}}}_{\text {winter }}\right)$, which is a key driver of cross-shore wavedominated shoreline evolution (Dodet et al., 2019), varies between $1.5 \mathrm{~m}$ and $3 \mathrm{~m}$ with a 
238 statistically significant decreasing trend under $0.05 \mathrm{~mm} /$ year in both RCP scenarios (Figure 2e).

239 This is consistent with previous regional projections (Charles et al., 2012; Perez et al., 2015;

240 Morim et al., 2019).

\subsubsection{Past mean sea level reconstruction}

As SLR-driven shoreline retreat is explicitly accounted for in the calibration of the shoreline models, past MSL information is required. We reconstructed the geocentric MSL change in the Bay of Biscay over the period 2012-2020 using a Kalman filter approach assimilating available tide gauge records in this region (Rohmer \& Le Cozannet, 2019). The resulting SLR rates are roughly constant at $2.1 \pm 0.1 \mathrm{~mm} /$ year $($ median $\pm \sigma)$. Local relative MSL change at Truc Vert beach was calculated by adding the effect of vertical land motion to the relative regional sea level estimate. Vertical land motion in Truc Vert area was estimated using the near Cap-Ferret permanent GNSS station from the SONEL database (Santamaria-Gomez et al., 2017), which provides data from 2005 to 2012, when the station was decommissioned. The GNSS station measures the effects of Glacial Isostatic Adjustment and current gravitational, rotational and deformation changes associated to ongoing glaciers and ice-sheets melting (Frederikse et al., 2020). We subtract their effects from the observed GNSS records over the observation period to assess residual vertical ground motions obtaining a subsidence rate of $1.2 \pm 0.6 \mathrm{~mm} / \mathrm{yr}$. This results in a roughly constant SLR rate of $3.3 \pm 0.7 \mathrm{~mm} / \mathrm{yr}$ over the past decade (see Figure $\mathrm{S} 5$ of Supporting 
Information). The observed lowering ground might be due to slow subsidence of the former Leyre riverbed (Klingebiel \& Legigan, 1992).

The pointwise Cap-Ferret GNSS station information may not be exactly that of the surrounding area. This is part of the residual uncertainties of our study.

\subsubsection{Future mean sea level projections}

State-of-the-art GMSL projections until 2100 are available from the Special Report of Ocean and Cryosphere in a Changing Climate (SROCC, Oppenheimer et al., 2019). SROCC estimates build on the Fifth Assessment Report (AR5, Wong et al., 2014) with a revised assessment of the Antarctic dynamics contribution based on new evidence on marine ice-sheets instabilities since the AR5. SROCC provides median values of each sea level change contribution with associated likely range for several RCP scenarios. Unlike other IPCC reports, the SROCC defines the likely range as the $17^{\text {th }}-83^{\text {rd }}$ percentiles of the distribution of sea-level rise (Oppenheimer et al., 2019). We reproduced the SROCC global MSL projections to Truc Vert beach following Thiéblemont et al. (2019) and considering the regional fingerprints of each mechanism contributing to sea-level changes, including the effect of Glacial Isostatic Adjustment (Slangen et al., 2014). This results in regional relative 2020-2100 SLR estimate (median and likely range) of $0.63 \pm 0.26 \mathrm{~m}$ and $0.37 \pm 0.16 \mathrm{~m}$ for the RCP8.5 and RCP4.5 scenarios, respectively.

Residual vertical land motion, which is assumed to be due to slow-ongoing geological processes (see subsection 2.3.1 and Klingebiel \& Legigan, 1992), is assumed to remain constant (1.2 \pm 0.6 $\mathrm{mm} / \mathrm{yr})$ over the $21^{\text {st }}$ century. Due to the large uncertainty $(0.6 \mathrm{~mm} / \mathrm{yr})$ of the subsidence rate, the stability of the area is not excluded, but has a very low probability $(2.1 \%)$. The inclusion of ground motion results in a local relative MSL rise of $0.73 \pm 0.27 \mathrm{~m}$ and $0.47 \pm 0.17 \mathrm{~m}$ from 2020 to 2100 
279 for RCP8.5 and RCP4.5 scenarios, respectively (see Figure S5 in Supporting Information). Further 280 detail on future SLR is provided in Section 3.1.

282 Here, we use two equilibrium-based models to assess wave-driven shoreline response: the Yates et al. (2009) model, and an adaptation of the ShoreFor model (Davidson et al., 2013; Splinter et al. 2014a). As the Truc Vert bathymetry iso-contours are essentially shore-parallel, breaking wave conditions were computed directly from offshore wave conditions using the Larson et al. (2010) formula. Chronic shoreline retreat induced by SLR was estimated using the Bruun (1962) model. As shoreline change at Truc Vert is known to be dominated by cross-shore sediment transport with negligible gradients in longshore transport (Castelle et al., 2014; Splinter et al., 2014a), we did not compute longshore sediment transport. The following subsections describe the two wave-driven shoreline models and the Bruun model.

\subsubsection{Wave-driven shoreline models and free parameters}

Equilibrium shoreline models are based on the principle that local wave climate drives the shoreline towards a time-varying equilibrium position at a rate that depends on the instantaneous wave thrust (e.g. wave power or energy) available to move the sediment, and the dynamic disequilibrium state of the beach (Wright \& Short, 1984). The Yates et al. (2009) model and ShoreFor differ primarily in the formulation of the respective disequilibrium conditions.

\subsubsection{ShoreFor model}

The ShoreFor model (hereafter SF) adopts a disequilibrium condition based on the wave history, expressed as a disequilibrium of dimensionless fall velocity $(\Delta \Omega)$ and its standard deviation $\left(\sigma_{\Delta \Omega}\right)$. The governing equation for shoreline change rate reads: 


$$
\frac{d Y}{d t}=k_{s}{ }^{+/-} \mathrm{P}^{0.5} \frac{\Delta \Omega}{\sigma_{\Delta \Omega}}+b
$$

where, $k_{s}^{+/-}\left(\mathrm{m} \mathrm{s}^{-1} \mathrm{~W}^{-0.5}\right)$ is a response rate parameter, $P(\mathrm{~W})$ is the wave power at breaking, and $b(\mathrm{~m} / \mathrm{s})$ is a linear term trend. Following Robinet et al. (2018), the disequilibrium term $\Delta \Omega$ at a given time is defined as the difference between the equilibrium dimensionless fall velocity $\left(\Omega_{\mathrm{eq}}(\Phi)\right)$ and the offshore dimensionless fall velocity $\left(\Omega_{\mathrm{o}}\right)$, where $\Omega_{\mathrm{eq}}(\Phi)$ is a function of the sediment size, prior wave conditions, and the free parameter $\Phi$. The parameter $\Phi$ (days) is a site-specific 'beach memory', and defines the time over which a given wave event has an impact over the equilibrium state of the beach. The $k_{s}^{+/-}$parameter is the shoreline response rate, and assumes different values for accretion $\left(k_{s}{ }^{+}, \Delta \Omega>0\right)$ and erosion $\left(k_{s}{ }^{-}, \Delta \Omega<0\right)$ events, which are driven by different processes associating different time scales. The values of the $k_{\mathrm{s}}^{+/-}$parameter for accretion and erosion conditions are considered proportional through a coefficient $r\left(k_{s}^{-}=r k_{s}^{+}\right)$. The $r$ coefficient is not a model free parameter but is defined by the wave forcing, and is such that no trend in wave forcing results in no trend in the modelled shoreline position over the simulated period:

$$
r=\left|\frac{\sum_{i=1}^{N}\left\langle F^{+}\right\rangle}{\sum_{i=1}^{N}\left\langle F^{-}\right\rangle}\right|
$$

$$
F=\mathrm{P}^{0.5} \frac{\Delta \Omega(\Phi)}{\sigma_{\Delta \Omega}}
$$

where $N$ is the full length of the simulated period, $F^{+}$and $F^{-}$are the forcing during accretion $(\Delta \Omega$ $>0)$ and erosion $(\Delta \Omega<0)$ events, respectively, and $\langle$.$\rangle denotes an operation that removes the linear$ trend. Here, the sign of $\Delta \Omega$ does not change the absolute value of $F^{+/-}$. For an extended description of SF the reader is referred to Davidson et al. (2013) and Splinter et al. (2014a). In SF, the model free parameters to be calibrated at a given site are $k_{s}^{+}, \Phi$ and $b$. Physically, the $k_{s}^{+/-}\left(\mathrm{m} \mathrm{s}^{-1} \mathrm{~W}^{-0.5}\right)$ is a measure of the efficiency of wave forcing to drive shoreline change (as described by Splinter et al., 2014a), which can also be interpreted as a time scale of shoreline response (Vitousek et al., 
2021). Indeed, a low efficiency corresponds to a slow shoreline response and a longer time scale, and vice versa. $\Phi$ (days) is a time scale for the duration of the impact that past waves exerted on the beach, and provides the ability for the model equilibrium condition to evolve along with longterm wave energy trends. The parameter $b(\mathrm{~m} / \mathrm{s})$ is a linear term that encapsulates the effect of slow processes, other than wave-driven equilibrium based, which may drive chronic shoreline change (e.g. wind driven sediment transport) and that are not explicitly resolved in the model. We note here that, while accounting for the effects of slow processes using a constant linear trend (i.e. $b$ ) can improve the model skill for simulated periods within the decade, the application of such trend over longer time scales (decades to centuries) becomes increasingly inaccurate (D'Anna et al., 2020). Therefore, given the long time scale of our application and the absence of secondary processes (e.g. longshore gradients in sediment transport) that may drive long-term shoreline trends at Truc Vert, we set $b=0$.

\subsubsection{Yates model}

In Yates' model (hereafter Y09) the disequilibrium condition is defined as a function of the current shoreline position, and the cross-shore rate of shoreline change is calculated as follows:

$$
\frac{d Y}{d t}=k_{y}^{+/-} E^{0.5}\left(E_{e q}(Y)-E\right)
$$

where $E\left(\mathrm{~m}^{2}\right)$ is the wave energy, $k_{y}{ }^{+/-}\left(\mathrm{m}^{2} \mathrm{~s}^{-1} / \mathrm{m}\right)$ is the response rate parameter, $Y(\mathrm{~m})$ is the present shoreline position, and $E_{\mathrm{eq}}(Y)$ is the wave energy in equilibrium with the current shoreline position $Y$ through a linear relationship:

where $a_{1}\left(\mathrm{~m}^{2} / \mathrm{m}\right)$ and $a_{2}\left(\mathrm{~m}^{2}\right)$ are free model parameters. The $k_{y}{ }^{+/-}$parameter is analogous to $k_{s}{ }^{+-}$of $\mathrm{SF}$ in that it represents the efficiency rate of the incident wave forcing to shoreline change, or a time scale parameter (see the analytical derivation of the Y09 time scale of shoreline response in 
Vitousek et al., 2021). In the Y09 model no assumption is made on a possible relationship between the $k_{y}{ }^{+}$and $k_{y}{ }^{-}$, which are both considered model free parameters and, as well as $a_{1}$ and $a_{2}$, require specific calibration for each field site application. Contrarily to SF, here the equilibrium state formulation (Equation 5) does not depend on recent wave conditions, making this model insensitive to wave-climate variability on timescales longer than the calibration period. Instead, Equation 5 depends on the current shoreline position $(Y)$, introducing the potential for feedbacks between Y09 and shoreline change induced by other cross-shore processes (e.g. SLR). Herein, such processes are resolved independently and linearly superposed, so that no feedback is enabled. Physically, $k_{y}{ }^{+/}$, once again is a measure of the shoreline reactivity to the incident wave forcing, and is expressed in $\left(\mathrm{m} \mathrm{s}^{-1} / \mathrm{m}\right)$. Although the dimensions of $a_{1}$ and $a_{2}$ are 'energy/meter' and 'energy', respectively, the role of these parameters in the model is purely empirical. A rearrangement of the terms in Equations 2-3 results in combinations of model parameters that are representative of equilibrium time and spatial scales (Vitousek et al., 2021). However, here we use Y09 in its original form, where $a_{1}$ and $a_{2}$ are treated as empirical parameters.

\subsubsection{Sea-level driven shoreline recession}

We include SLR-driven shoreline recession using the Bruun (1962) model, which is based on the equilibrium beach concept and cross-shore balance of sediment volume. While the reliability of this model is highly debated for its oversimplification of the reality (Cooper \& Pilkey, 2004; Ranasinghe, 2012), its simple linear formulation has been extensively used worldwide. In addition, Truc Vert beach is a relatively undisturbed beach-dune environment with large accommodation space, which makes this sites in line with most of the Bruun Rule underlying assumptions. The Bruun model assumes that under rising sea level, on time scales larger than years, the average beach profile translates upwards and landwards. The resulting shoreline retreat ( $\left.\mathrm{dY}_{\mathrm{SLR}} / \mathrm{dt}\right)$ depends 
on SLR and the average slope of the active beach profile, here extending from the dune crest down to the depth of closure (DoC), defined as the depth beyond which sediment exchange is considered negligible (Bruun, 1988; Wolinsky \& Murray, 2009):

$$
\frac{d Y_{S L R}}{d t}=\frac{S L R_{\text {rate }}}{\tan \beta}
$$

where $S L R_{\text {rate }}$ is the rate of SLR (m/time), and $\tan \beta$ is the average profile slope defined between the DoC and the dune crest. We estimated the DoC according to Hallermeier (1978), and the corresponding $\tan \beta=0.023$ using the beach profile reported in Figure 1c.

\subsection{Global Sensitivity Analysis}

Numerical modelling of shoreline change inherits the uncertainties associated to input variables and their complex interactions, affecting the robustness of the shoreline projections. While numerical modelling provides a 'key-hole' to observe the explicit interactions among defined sets of variables, sensitivity analysis provides a way to understand the role of input variables uncertainties in shoreline predictions. Here, we use the framework proposed by D'Anna et al. (2020), who used a variance-based Global Sensitivity Analysis (GSA) (Saltelli et al., 2008; Sobol', 2001) to investigate the relative contributions of the uncertainties affecting input variables to the uncertainties of modelled shoreline predictions, and their evolution in time. The method consists in propagating the input uncertainties through the model obtaining a probabilistic estimate of the shoreline projections, and performing a GSA which decomposes the variance of model results into several contributions, each one associated with an input variable. Each of these contributions is used to estimate a measure of the model results sensitivity to the input uncertainties with a sensitivity index known as first-order Sobol' index $\left(S_{i}\right)$. The $S_{i}(0-1)$ quantifies the ratio of output's 
variance associated with the uncertainties of a given input $X_{\mathrm{i}}$, i.e. the reduction in the output variance that would occur if the uncertain input $X_{\mathrm{i}}$ was set to its true value, and is defined as:

$$
S_{i}=\frac{\operatorname{Var}\left(E\left(Y \mid X_{i}\right)\right)}{\operatorname{Var}(Y)}
$$

where $\operatorname{Var}$ is the variance operator, $E$ is the expectation operator, $Y$ is the modelled shoreline position, and $X_{i}$ is the $\mathrm{i}$-th uncertain input variable. Further details on GSA and $S_{i}$ are provided in Text S3 of Supporting Information.

Here, we address the relative impact of uncertainties associated to SLR, DoC and of model free parameters on shoreline projections $(Y)$ and their evolution in time for the two different modelling approaches described in Section 2.4. Identifying the main source of model results uncertainties through time is a fundamental step towards improving the reliability of long-term shoreline projections. Following D'Anna et al. (2020), we computed the $S_{i}$ s using the modularized samplebased approach by Li and Mahadevan (2016), which allows accounting for the statistical dependence between model free parameters, and we estimate $S_{i}$ s for the purpose of "Factors' Prioritization" (as defined by Saltelli et al., 2008). At a given time, the Factors' Prioritization identifies the main driver of model results uncertainty (associating the largest $S_{i}$ ), that is, the uncertain input variable that would most reduce the output's variance when fixed to its true value. The method can be summarized in three steps:

1) Definition of probability distribution associated to each stochastic input variable (SLR, DoC and model free parameters);

2) Generation of ensemble modelled shoreline projections, by means of a Monte-Carlo-based procedure (with accounts for dependence among the input parameters); and

3) Computation of first-order Sobol' index time series for each uncertain input variable. 
412 The GSA results are interpreted as the repartition of the variance of shoreline projections into

413 normalized portions (between 0 and 1) imputed to the uncertain input variables. For instance, at a

414 given time, $S_{i, \mathrm{SLR}}=0.3$ means that uncertainties in future SLR alone are responsible for $30 \%$ of the

415 variance in shoreline projections. However, the magnitude of a $S_{i}$ alone is not sufficient to identify

416 the main driver of the shoreline projections' variance, which is defined by comparing the values

417 of $S_{i}$ for all input variables and ranking them in terms of importance.

418 Figure 3 synthesizes the generalized method and details for the Truc Vert probabilistic applications

419 (excluding the additional high-end SLR deterministic scenario).

420

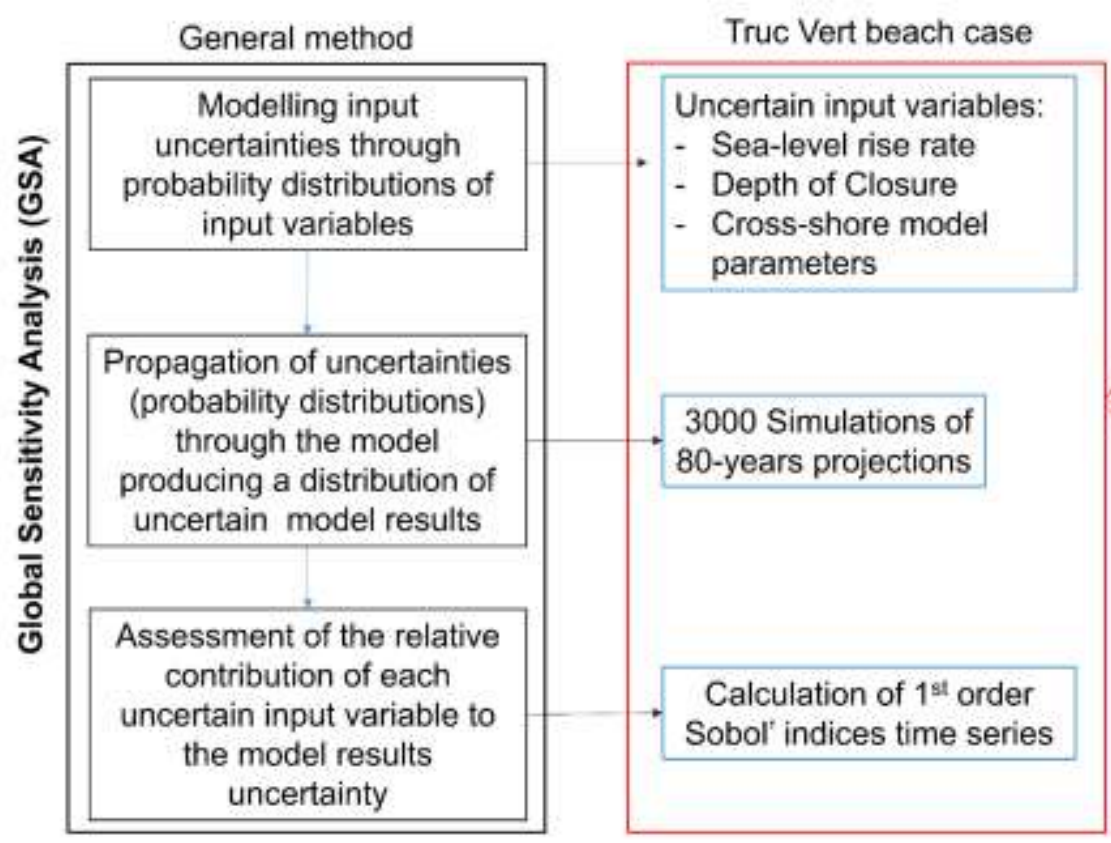

ShoreFor RCP 4.5

Shorefor RCP 8.5

Yates RCP 4.5

Yates RCP 8.5

Figure 3 Flowchart of the method applied herein, summarized for a general case (black box), and for the Truc Vert application (red box) in the four application scenarios.

\section{Input probability distributions for future projections}

\subsection{Probabilistic sea-level rise}

Sea-level projections inherit uncertainties associated with physical unknowns and modelling of the contributing processes. While many efforts were dedicated to assess such uncertainties, there is no 
427 single approach to define MSL probability distributions yet (Jackson \& Jevrejeva, 2016; Jevrejeva et al., 2019; Kopp et al., 2014). We produced probabilistic relative MSL projections, conditional to the RCP8.5 and 4.5 scenarios, defining time varying normal probability distributions characterized by the yearly median and standard deviations obtained in Section 2.3.2 (Figure 4a,b), following Hunter et al. (2013). In the high-emission scenario (RCP8.5), the large uncertainty associated with Antarctic ice sheet dynamics generates a skewness of the distributions in the second half of the $21^{\text {st }}$ century, enhancing the amount of possible extreme SLR (Grinsted et al., 2015; Jackson \& Jevrejeva, 2016; Kopp et al., 2014). The upper tail of the skewed probability distribution is very much debated (Jevrejeva et al., 2019) and is not represented by the Gaussian distributions. Therefore, in addition to the Gaussian distribution reflecting the SROCC assessment (Oppenheimer et al., 2019), we consider a high-impact, low probability high-end sea level scenario that might take place for high greenhouse gas emissions (RCP8.5; black line in Figure 4b) following the same assumptions as Thiéblemont et al. (2019) (see Text S2 in Supporting Information for details).

The possibility that the subsidence rate revealed by the Cap-Ferret GPS station is not representative of the Truc Vert area (located at $8 \mathrm{~km}$ distance) constitutes a residual uncertainty that cannot be quantified, and is not accounted in this study due to the lack of quantitative information supporting an alternative scenario for residual vertical ground motions.

\subsection{Depth of closure}

The active beach profile slope is critical to SLR-driven erosion rate (Section 2.4), and strongly depends on the depth of closure (DoC). The DoC was calculated from the wave climate using the Hallermeier (1978) formula. Given that DoC depends on the period of time over which the Hallermeier formula is applied (Nicholls, 1998), we iteratively applied the Hallermeier formula 
over a 1-year moving window of the future wave climate with a 30-days step. For both RCP8.5 and RCP4.5 scenarios, the latter procedure generated an ensemble of possible DoC values well fitted by a Gaussian distribution (Figure 4c). The DoC probability distribution shows higher median and standard deviation values in the RCP4.5 $(\mu=17.2 \mathrm{~m} ; \sigma=1.75 \mathrm{~m})$ than in the RCP8.5 $(\mu=16.3 \mathrm{~m} ; \sigma=0.95 \mathrm{~m})$. This results from the more frequent occurrence and larger wave heights associated to isolated extreme events in the RCP4.5 scenario, compared to the RCP8.5 scenario.

\subsection{Model parameters}

Numerical models are associated with uncertainties owing to the choice of modelling approach and to the estimation of model free parameters. We accounted for the uncertainty conditional to the choice of modelling approach assessing the shoreline projections using the Y09 and the SF models described in Section 2.4.1, in two separated scenarios. Both models rely on shoreline observations to calibrate the respective free parameters, and inherit uncertainties due to the quality and amount of available data (Splinter et al., 2013), to possible non-stationarity of the parameters in respect to the wave climate (Ibaceta et al., 2020), and to the optimization method. Uncertainties affecting model free parameters of the Y09 model $\left(k_{y}{ }^{+/-}, a_{1}, a_{2}\right)$ and the SF model $\left(k_{s}^{+}, \Phi\right)$ are synthetized by their associated joined probability distribution. We follow the approach developed in D'Anna et al. (2020), who calibrated the SF model free parameters using the Simulated Annealing algorithm (Bertsimas \& Tsitsiklis, 1993), and determined their joint probability distribution by fitting an empirical multivariate distribution (multivariate kernel function) on an ensemble of model parameters combinations. The authors built the latter ensemble selecting all parameters combinations that produced a RMSE $<10 \mathrm{~m}$ against observed shoreline data during the optimization process. Unlike D'Anna et al. (2020), here we calibrated the models between January 2012 and December 2019, where no long-term trend in shoreline position is observed, in 
473 line with the assumption of the SF parameter $b=0$ (see Section 2.4.1). In addition, we used the 474 Nash-Sutcliffe (Nash \& Sutcliffe, 1970) efficiency score (NS) instead of the RMSE to determine 475 the models' performance (as for instance in Kroon et al., 2020). The NS measures the model skill 476 in comparison to the 'mean model' (defined as the observed mean shoreline position), based on 477 the error's variance, and it is calculated as follows:

$$
N S=1-\frac{\sum_{n=1}^{N}\left(Y_{m}{ }^{n}-Y_{o}{ }^{n}\right)^{2}}{\sum_{n=1}^{N}\left(\bar{Y}_{o}-Y_{o}^{n}\right)^{2}}
$$

where $N$ is the number of observations, $Y_{m}{ }^{n}$ and $Y_{o}{ }^{n}$ are the n-th modelled and observed shoreline positions, respectively, and $\bar{Y}_{o}$ is the mean of the observed shoreline positions. The NS coefficient can range between $-\infty$ and 1 , where $N S=1$ corresponds to a model perfectly reproducing the observations, $N S=0$ to a model with skill comparable to the 'mean model', and $N S<0$ corresponds to models less skilful than the 'mean model'. We obtained the probability distribution using combinations of parameters that resulted in a $N S \geq 0.25$ (compared to the maximum $N S=0.63$ ), which corresponds to a max RMSE of $\sim 10$ m consistently with D'Anna et al. (2020). We defined the latter threshold with the iterative procedure described in Text S4 of Supporting Information. This procedure results in the probability distributions of $k_{y}{ }^{+/-}, a_{1}$, and $a_{2}$ for $\mathrm{Y} 09$, and $k_{s}{ }^{+}$and $\Phi$ for SF shown in Figure 4d,e, with the range of possible parameters values reported in Table 1. 

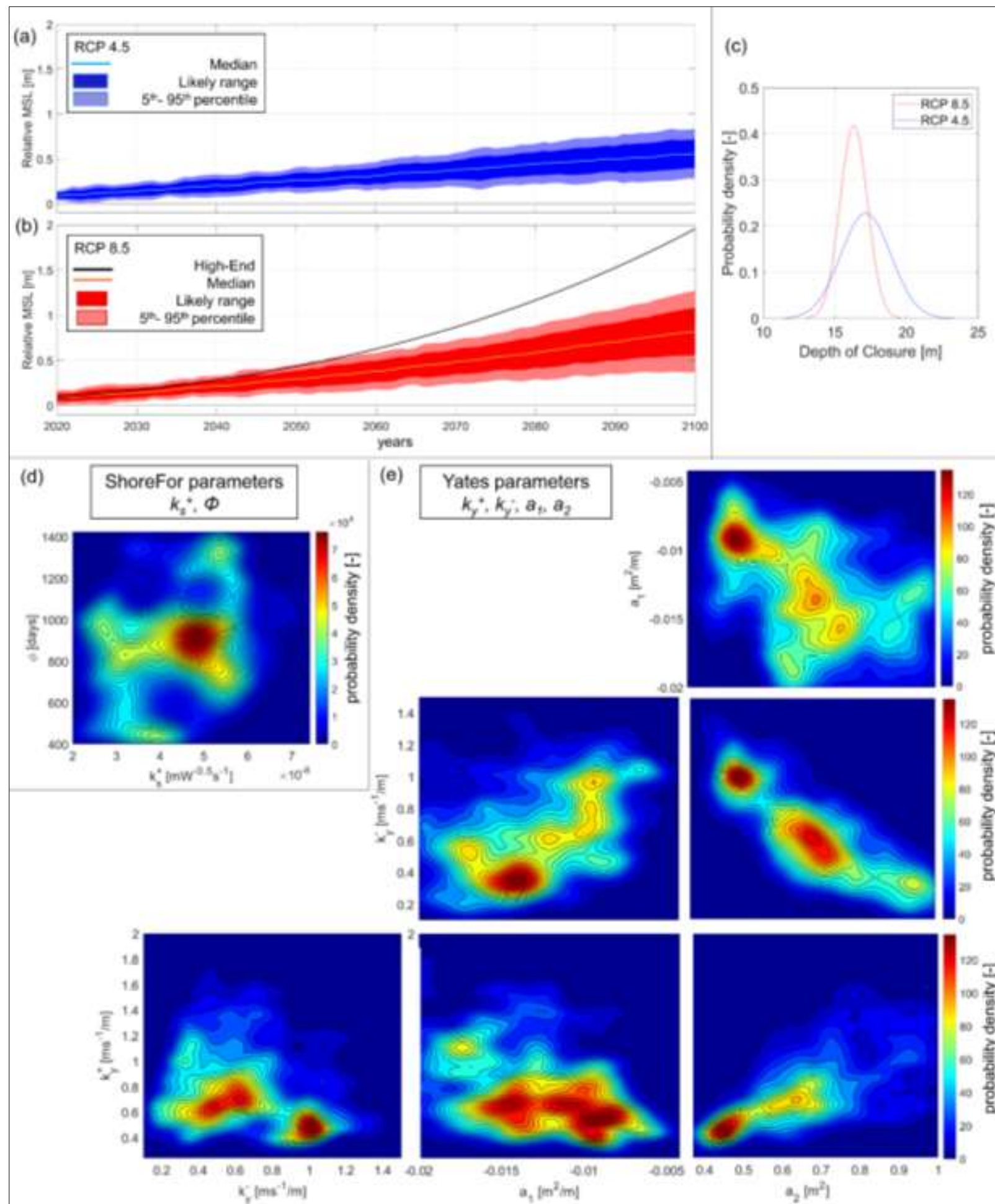

$$
\text { Figur }
$$

Figure 4 Probability distributions of: relative mean sea level over the period 2020-2100, including

492 the likely (dark shaded areas) and $5^{\text {th }}$ to $95^{\text {th }}$ percentile (light shaded areas) ranges, for (a) RCP4.5 493 and (b) RCP8.5 scenarios, with deterministic high-end sea-level projections based on 2100 high- 
494 end 'highest-modelled' estimates following Thiéblemont et al. (2019) (black line); (c) Gaussian 495 distributions of depth of closure values calculated over the 2020-2100 wave time series for RCP4.5

496 (blue curve) and RCP8.5 (red curve) scenarios; and empirical joint probability distributions of (d) 497 ShoreFor $\left[k_{s}{ }^{+}, \Phi\right]$ parameters, and (e) Yates $\left[k_{y}{ }^{+/}, a_{1}, a_{2}\right]$ parameters, obtained fitting a kernel 498 density function (with bandwidths estimated from the marginal kernel density function for each 499 variable) on 6000 combinations of model parameters producing $N S>0.25$ against shoreline data.

501 Table 1 Optimised combinations of cross-shore model free parameters, and respective range of 502 variation in the probability distributions.

\begin{tabular}{|c|c|c|c|}
\hline Model & Model parameter & $\begin{array}{c}\text { Optimised } \\
\text { value }\end{array}$ & $\begin{array}{c}\text { Distribution } \\
\text { range }\end{array}$ \\
\hline \multirow{4}{*}{ ShoreFor } & $k_{s}{ }^{+}\left[\mathrm{m}^{1.5} \mathrm{~s}^{-1} \mathrm{~W}^{0.5}\right]$ & $4.4 \times 10^{-8}$ & {$[2 ; 7.4] \times 10^{-8}$} \\
\cline { 2 - 4 } & $\Phi[\mathrm{days}]$ & 1193 & {$[400 ; 1423]$} \\
\hline \multirow{4}{*}{ Yates } & $k_{y}{ }^{+}\left[\mathrm{m}^{2} \mathrm{~s}^{-1} / \mathrm{m}\right]$ & 0.87 & {$[0.24 ; 2]$} \\
\cline { 2 - 4 } & $k_{y}{ }^{-}\left[\mathrm{m}^{2} \mathrm{~s}^{-1} / \mathrm{m}\right]$ & 0.5 & {$[0.1 ; 1.5]$} \\
\cline { 2 - 4 } & $a_{1}\left[\mathrm{~m}^{2} / \mathrm{m}\right]$ & -0.008 & {$[-0.02 ;-0.004]$} \\
\cline { 2 - 4 } & $a_{2}\left[\mathrm{~m}^{2}\right]$ & 0.49 & {$[0.33 ; 1]$} \\
\hline
\end{tabular}

503

504

505

506

507

508

509

3.4 Model setup of shoreline projections

Four ensembles of 3000 possible shoreline trajectories from 2020 to 2100 were generated using the SF and Y09 shoreline change models, and the Bruun Rule, for the two RCP8.5 and RCP4.5 scenarios (Table 2). Wave-driven shoreline response (short-term) and SLR (long-term) were computed individually and then linearly combined, so that no feedback mechanisms occur between the models, in line with previous applications (D’Anna et al., 2020; Vitousek et al., 2017). 
For each model and RCP scenario, 3000 simulations were run with different combinations of model free parameters, DoC and SLR time series, sampled from the respective probability distributions. Shoreline change was computed with a 3-hour time step from the $1^{\text {st }}$ January 2020 to the $31^{\text {st }}$ December 2099 starting from the same shoreline position $\left(Y_{0}=0\right)$, and model outputs were recorded with a 2-weeks resolution. As the characteristics of the MSL probability distribution are time-dependent, we randomly sampled percentile values and extracted the corresponding MSL at each year. The ensemble projections character was synthetized by the likely range, defined here at each time step as the variance, and the envelope (min and max) of modelled shoreline positions, acknowledging that the latter is dependent on the number of simulations and the tails of the probability distributions. The impact of individual winters on shoreline projections is qualitatively discussed observing the distributions of shoreline positions corresponding to the most seaward and landward median shoreline position within each simulated annual cycle $\left(1^{\text {st }}\right.$ September to $31^{\text {th }}$ August). We analysed the decadal shoreline trends by filtering the modelled shoreline time series with a 5-year running mean. In addition, for RCP8.5 scenario, a deterministic high-end-SLR simulation was run with both shoreline models using the optimized model parameters (Table 1) and the median DoC. It is to be noted that the GSA results (i.e. $S_{i}$ s) are calculated on the likely range (variance) of the model results, regardless of the envelope of modelled shoreline positions.

Table 2 Probabilistic future scenarios for two Representative Concentration Pathways (RCP) and two different wave-driven modelling approaches, using the Bruun Rule and 3000 different combinations of model parameters, SLR percentile and DoC.

\begin{tabular}{|c|c|c|c|}
\hline Future scenario & $\begin{array}{c}\text { SLR-driven } \\
\text { shoreline change }\end{array}$ & $\begin{array}{c}\text { Wave-driven } \\
\text { shoreline change }\end{array}$ & $\begin{array}{c}\text { \# Combinations of } \\
\text { uncertain variables }\end{array}$ \\
\hline RCP 4.5 & Bruun Rule & ShoreFor (SF) & 3000 \\
\hline
\end{tabular}




\begin{tabular}{|c|c|c|c|}
\hline & & Yates (Y09) & 3000 \\
\hline \multirow{2}{*}{ RCP 8.5 } & \multirow{2}{*}{ Bruun Rule } & ShoreFor (SF) & 3000 \\
\cline { 3 - 4 } & & Yates (Y09) & 3000 \\
\hline
\end{tabular}

\section{Results}

\subsection{Shoreline projections}

The four future scenarios in Table 2 resulted each one in 3000 shoreline evolution simulations spanning 2020-2100 (Figure 5 and Figure 6). Figure 5c,d and Figure 6c,d represent the distribution of 3000 modelled shoreline positions at each recorded output time. All scenarios show a net erosion by 2100 , mostly driven by SLR (Table 3). All model ensembles also show large interannual variability that is essentially enforced by the interannual variability in incident winter-mean wave height (Figure 5a,b and Figure 6a,b). In the RCP8.5 (RCP4.5) scenario we observe a long-term 541 shoreline change pattern responding to alternating sequences of high- and low-energy winters with a period of $\sim 20$ years ( 10 years) and even longer (Figure 5a,e,f and Figure 6a,e,f).

Figure 5c,d (Figure 6c,d) show several episodes of rapid erosion driven by isolated extreme energy winters, for instance for the RCP8.5 (RCP4.5) scenario in winter 2030, 2076, and 2086 (2068, 2073 and 2085). The two wave-driven shoreline models (Y09 and SF) produce consistent shortand long-term shoreline cycles, with larger tendency to accretion in SF than in Y09 during

547 extended periods of low energy winters, for instance during 2050-2055 for RCP4.5 and 2060-2070 548 for RCP8.5 (Figure 5c,d and Figure 6c,d).

549 In the RCP4.5 emission scenario, the modelled 2020-2100 Truc Vert shoreline trend leads to a likely (envelope) retreat of 15 to $33 \mathrm{~m}$ (4 to $75 \mathrm{~m}$ ) with Y09, and 10 to $23 \mathrm{~m}$ (6 to $65 \mathrm{~m}$ ) with SF. 
551 On a yearly time scale, the shoreline position is likely (envelope) to be farther landward from the 552 initial position, by $76 \mathrm{~m}(123 \mathrm{~m})$ with Y09, and $43 \mathrm{~m} \mathrm{(74} \mathrm{m)} \mathrm{with} \mathrm{SF} \mathrm{(Figure} \mathrm{5c,d,} \mathrm{Table} \mathrm{3).} \mathrm{Indeed,}$

553 the occurrence of extreme winters can produce significant landward shifts of the envelope of 554 shoreline positions, as observed during the 2084-2085 winter (Figure 5c,d). 


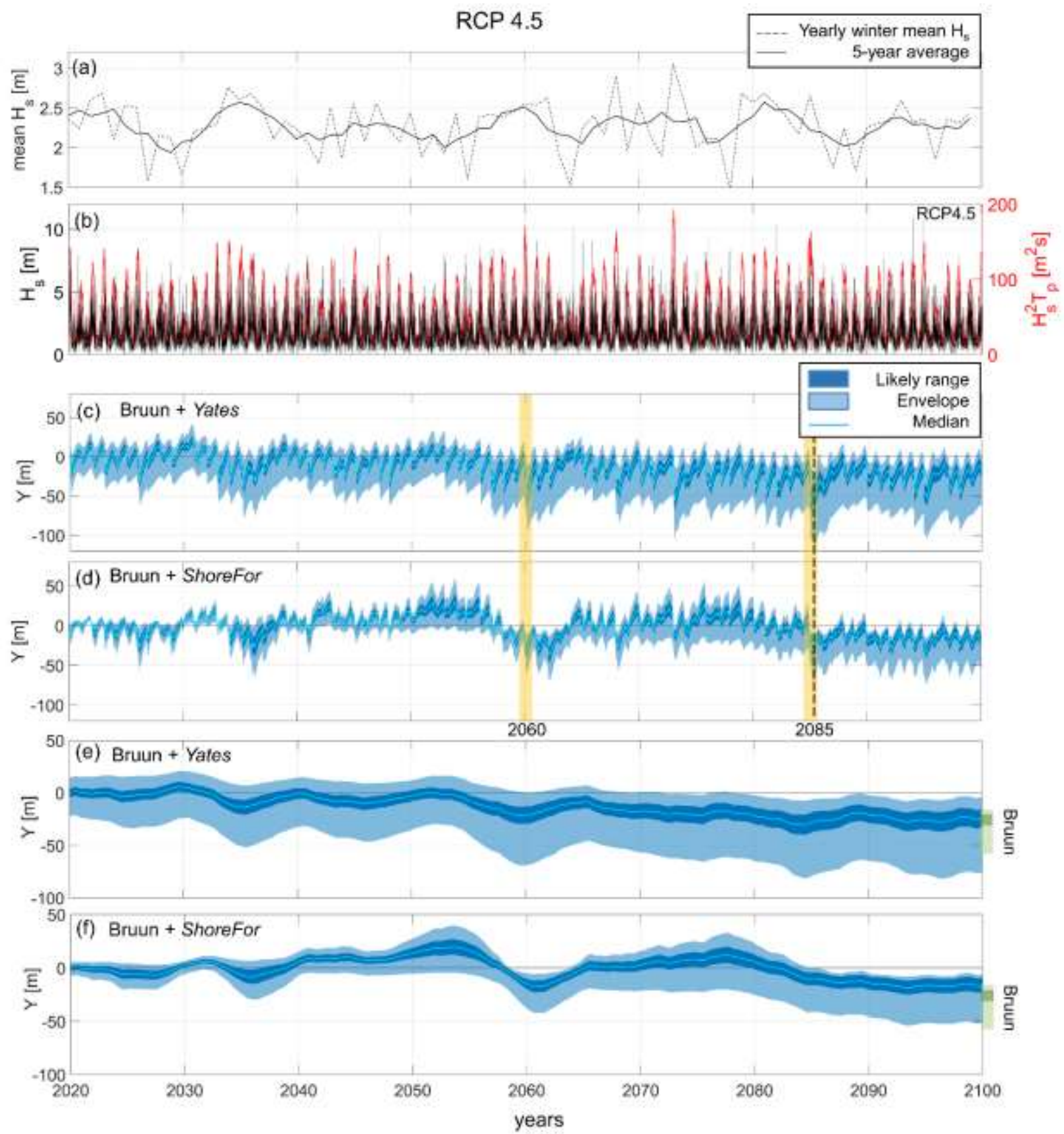

Figure 5 (a) Time series of winter mean wave height of the BW18 RCP4.5 projections (dashed line) with corresponding 5-year average (solid line); (b) BW18 RCP4.5 wave height time series (black line), and 3-month average $H_{s}^{2} T_{p}$ time series (red line); RCP4.5 scenario 2020-2100 shoreline projections at 14-days resolution obtained using (c) Y09 and (d) SF; and 5-year running mean shoreline projections modelled with (e) Y09, (f) SF, and the standalone Bruun Rule (green bars). Dark (light) blue shaded areas indicate the likely (envelope) range, i.e. variance (min-max), of shoreline position, and solid light line median shoreline position. The dashed vertical line 
564 indicates the most landward shoreline position over the simulated period. Yellow shaded areas 565 indicate examples of years including high-energy winters.

566 When forced with RCP8.5 scenario's wave and MSL projections, from 2020 to 2100 simulations 567 indicate an average likely (envelope) erosion of 27 to $48 \mathrm{~m}$ (16 to $83 \mathrm{~m}$ ) using Y09, and 14 to 33 $568 \mathrm{~m}(2$ to $67 \mathrm{~m}$ ) using SF (Figure 6d,e). In this scenario, over the simulated period the likely 569 (envelope) most landward shoreline position reaches up to $70 \mathrm{~m}(108 \mathrm{~m})$ from the initial shoreline 570 position with Y09 model, and $48 \mathrm{~m}$ (76 m) with SF (Figure 6c,d, Table 3). Similarly to the RCP4.5,

571 here we observe for both models some important shifts in shoreline position distribution owing to 572 extreme winters such as 2086's winter (Figure 6c,d).

573 In the high-end SLR scenario, both models predict a shoreline position within the envelope of 574 probabilistic projections until 2090, before the shoreline moves further inland during the last 575 decade (Figure 6d,e). The modelled 5-year averaged shoreline position in 2100 is of 88 and $74 \mathrm{~m}$ 576 for Y09 and SF, respectively (Table 3). The most landward shoreline position observed throughout 577 the simulation is $107 \mathrm{~m}$ with Y09, and $86 \mathrm{~m}$ with SF (black dashed line in Figure 6c,d).

578 The likely (envelope) ranges erosion produced by the combined Y09+Bruun models at the end of 579 the simulated period are comparable (larger) to the standalone application of the Bruun Rule (Table 580 3, and in Figure 5,6,e,f with Bruun model predictions in green). With the combined SF+Bruun 581 models, the likely (envelope) ranges of shoreline positions obtained show $\sim 10 \mathrm{~m}(\sim 15 \mathrm{~m})$ less 582 erosion than the Bruun Rule. 



Figure 6 (a) Time series of winter mean wave height of the BW18 RCP8.5 projections (dashed line) with corresponding 5-year average (solid line); (b) BW18 RCP8.5 wave height time series (black line), and 3-month average $H_{s}{ }^{2} T_{p}$ time series (red line); RCP8.5 scenario 2020-2100 shoreline projections at 14-days resolution obtained using (c) Y09 and (d) SF; and 5-year running mean shoreline projections modelled with (e) Y09, (f) SF, and the standalone Bruun Rule (green bars). Dark (light) shaded areas indicate the likely (envelope) range, i.e. variance (min-max), of 
shoreline position. Black solid lines indicate shoreline projections in the RCP8.5 high-end SLR scenario. The dashed vertical line indicates the most landward shoreline position over the simulated period. Yellow shaded areas indicate examples of years including high-energy winters.

Table 3 Likely (modelled shoreline variance) and envelope (min-max) values of the 5-year averaged projected shoreline position in 2100, and 2020-2100 most landward shoreline position, obtained using the standalone Bruun Rule (B), and the combined B with Y09 and SF equilibrium shoreline models, for the RCP4.5 and RCP8.5 probabilistic scenarios, and the deterministic highend SLR scenario.

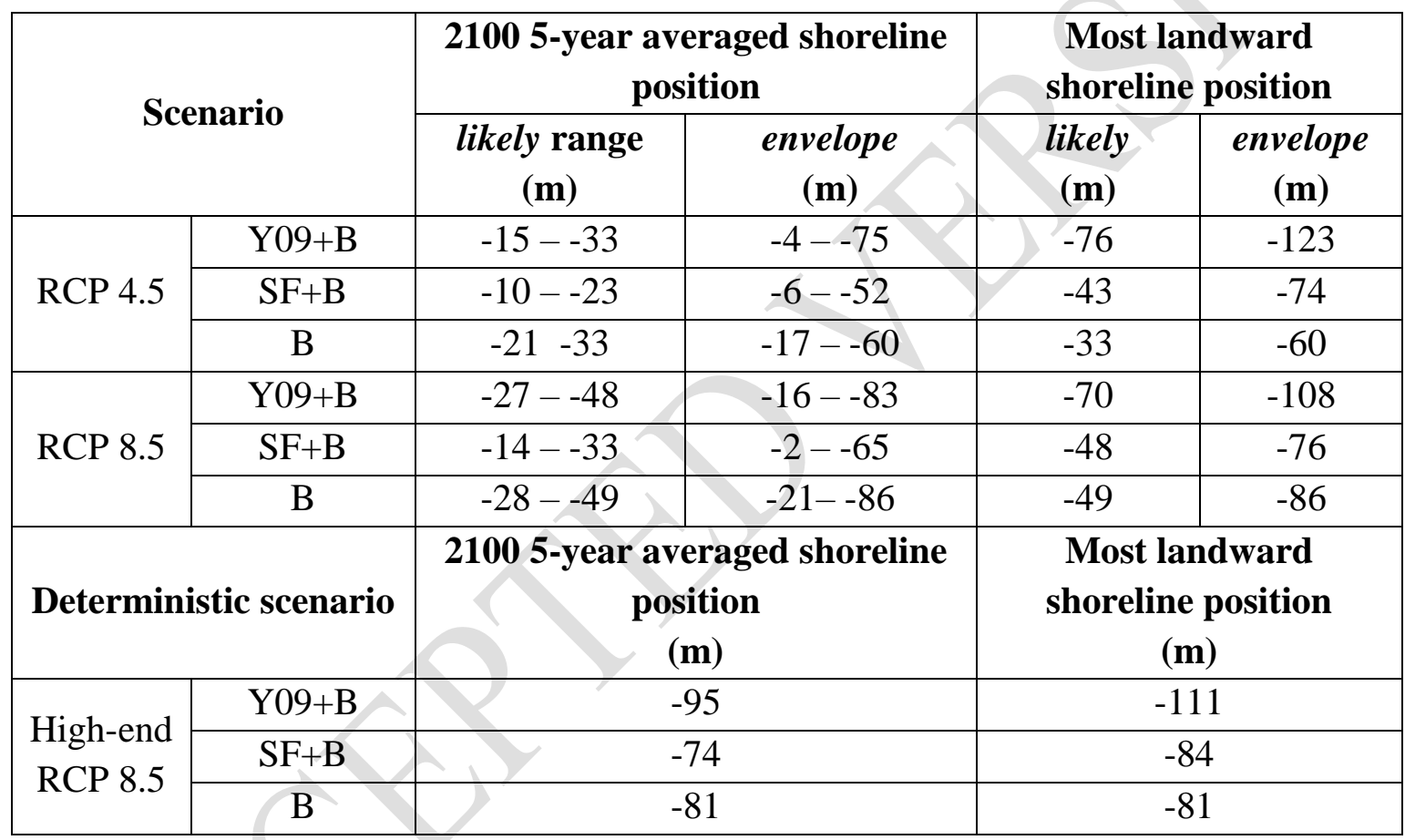
In both RCP8.5 and 4.5 scenarios and for both shoreline model applications, the GSA shows that over the first 30 years of simulation the variance of modelled shoreline projections is driven primarily by the uncertainties in model free parameters, while the effects of SLR uncertainties on shoreline position become increasingly significant after 2050 (Figure 7 and Figure 8 ). The $S_{i}$ s of the Y09 and SF response rate parameters $\left(k_{y}{ }^{+-}\right.$and $k_{s}{ }^{+}$, respectively) and the SF beach memory 
606

607

608

609

610

611

612

613

614

615

616

618

619

620

621

622

623

624

625

626

parameter $(\Phi)$ show seasonal (6 months) and decadal modulation with a decreasing trend as shoreline projections become more sensitive to SLR (Figure 7c,d and Figure 8c,d). Variations in $k_{y}{ }^{+/}$and $k_{s}{ }^{+}$are the primary source of shoreline projection uncertainties during accretion periods. However, the response rate parameters' uncertainties have a stronger impact on seasonal scale when using the Y09 model (Figure 7c), and a larger impact on interannual scale when using the SF model (Figure 8c), due to the different response of the models to incident wave energy variability. Seasonal modulation is also observed for the $S_{i}$ s of the Y09 empirical parameters $\left(a_{1}\right.$ and $a_{2}$ ), although the correlation between the variability in incident wave conditions and the parameters' $S_{i} \mathrm{~s}$, (both filtered of their seasonal signal with a 1-year running mean) is negligible $\left(\mathrm{R}^{2}=\sim 0.06\right.$ for $a_{1}$, and $\mathrm{R}^{2}=\sim 0.03$ for $\left.a_{2}\right)$. However, the estimated $a_{1}$ 's and $a_{2}$ 's $S_{i}$ s remain below $20 \%$ during most of the simulated period with occasional peaks up to $45 \%$ (Figure $7 \mathrm{e}, \mathrm{f}$ ). The primary effects of SLR uncertainties emerge at different times, which depend both on the RCP scenario and on the shoreline model. When using Y09, a positive trend in SLR's $S_{i}$ emerges in the 2050-2060 period, with SLR's $S_{i}$ exceeding those of model parameters since approximately 20602070, for both RCP scenarios (Figure 7g). Instead, with SF in the RCP8.5 (RCP4.5) scenario, such quasi-monotonic trend appears later, approximately during the 2070s' (2060s') and only exceeds the model parameters' $S_{i}$ s after 2085 (2080) (Figure 8e). For all scenarios, DoC's $S_{i}$ slowly increases, with similar trends as SLR's $S_{i}$, and reaches approximately 5\% and 10\%, in the RCP8.5 and 4.5 scenarios, respectively. This difference is probably due to the larger uncertainties of SLR in the RCP8.5 scenario (Figure 4b), and to the larger variance of the DoC probability distribution obtained for the RCP4.5 scenario (Figure 4c). 

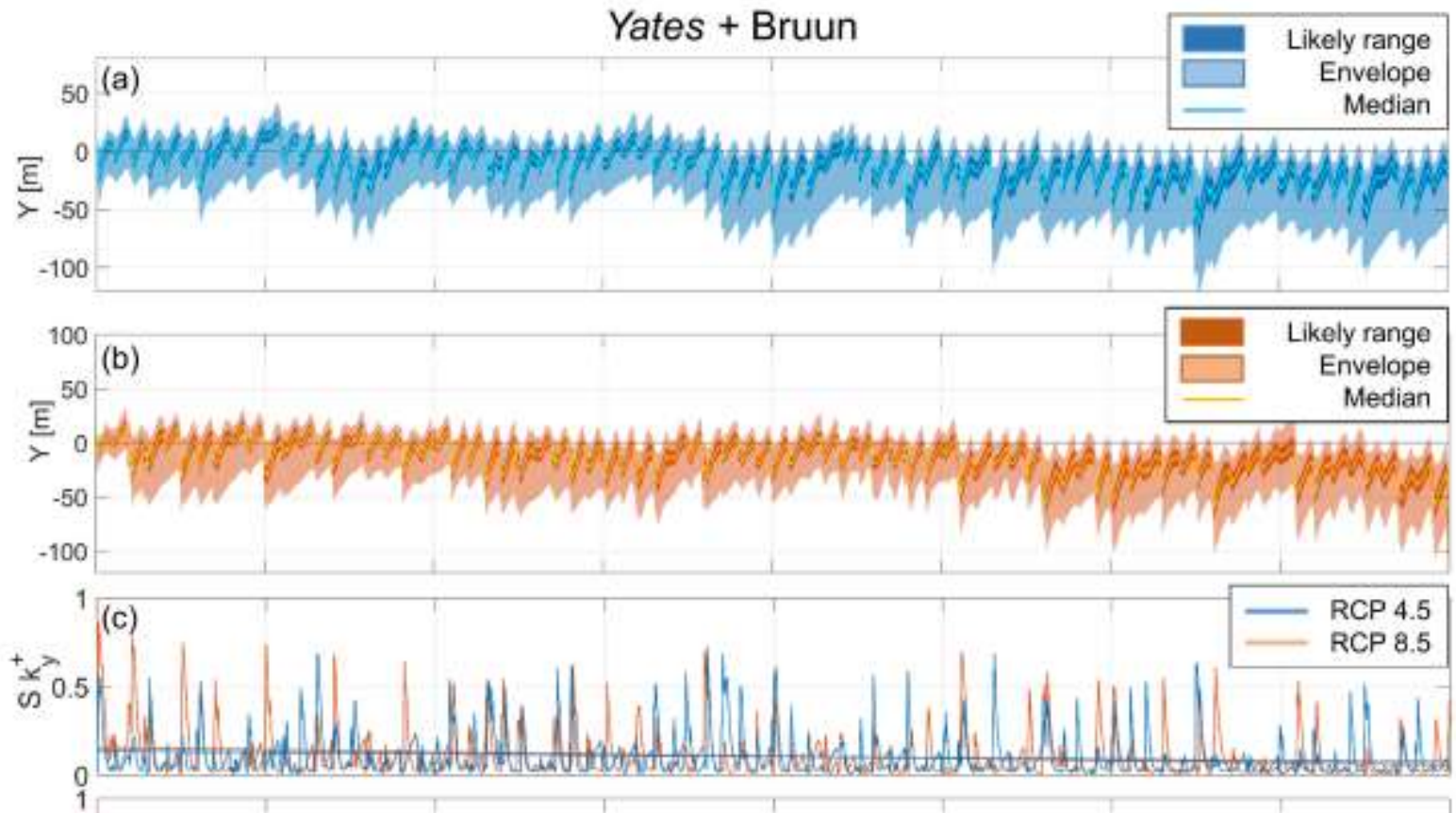

(d)

$\frac{x^{2}}{s^{2}} 0.5$

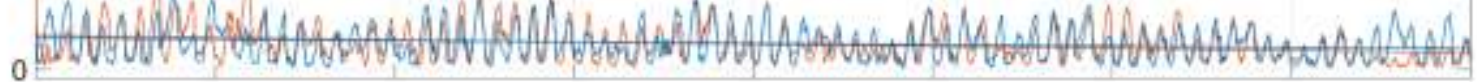
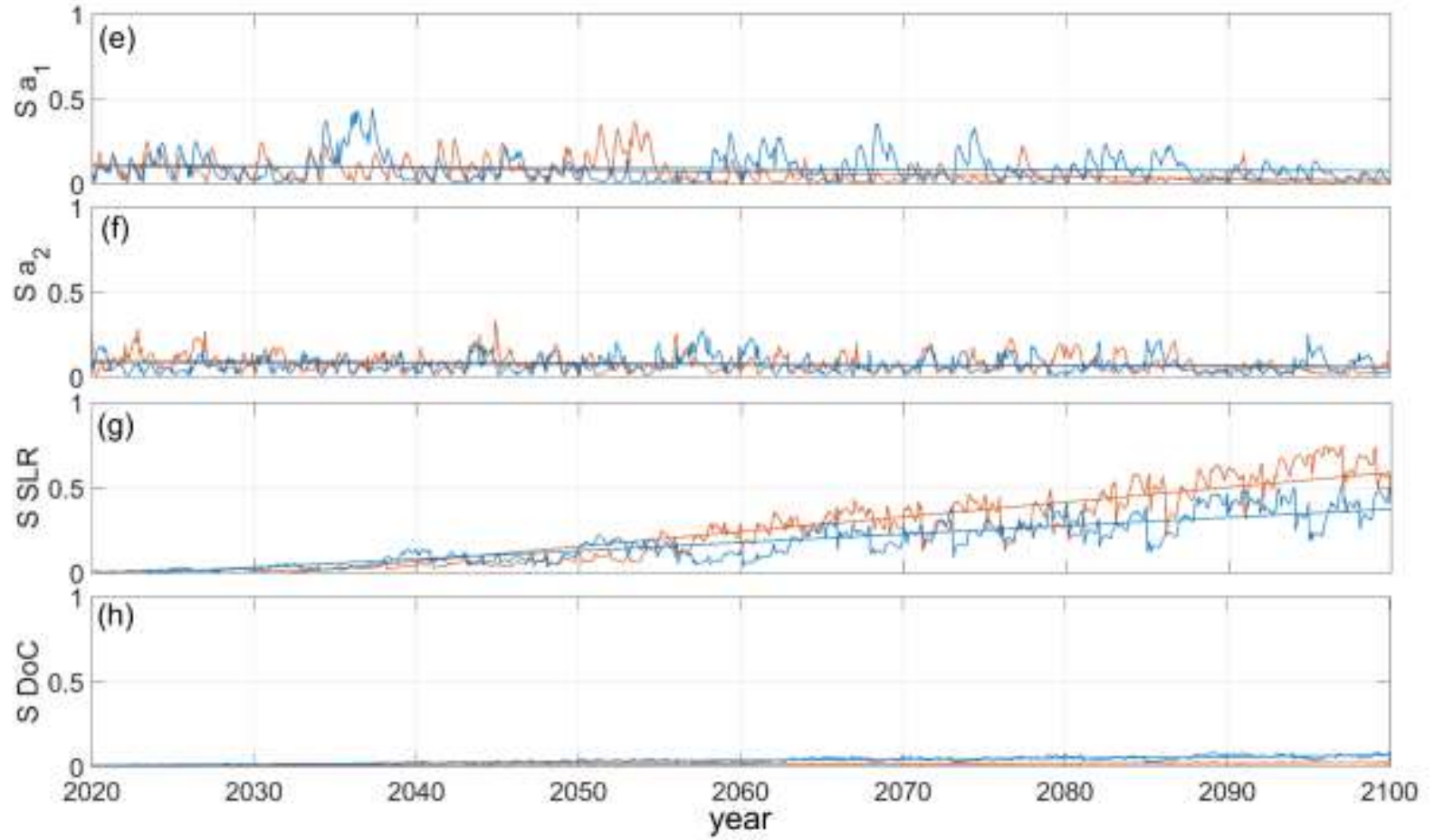

Figure 7 Global Sensitivity Analysis results over the period 2020-2100 using the Yates model in the RCP4.5 (blue lines) and RCP8.5 (orange lines) scenarios. (a) RCP4.5 and (b) RCP8.5 Ensemble shoreline projections (shaded areas) over 2020-2100; First-order Sobol' index time 
631 series for (c) $k_{y}{ }^{+}$, (d) $k_{y}{ }^{-}$, (e) $a_{1}$, (f) $a_{2}$, (g) sea-level rise, and (h) depth of closure, with respective 632 linear fit (solid straight lines).
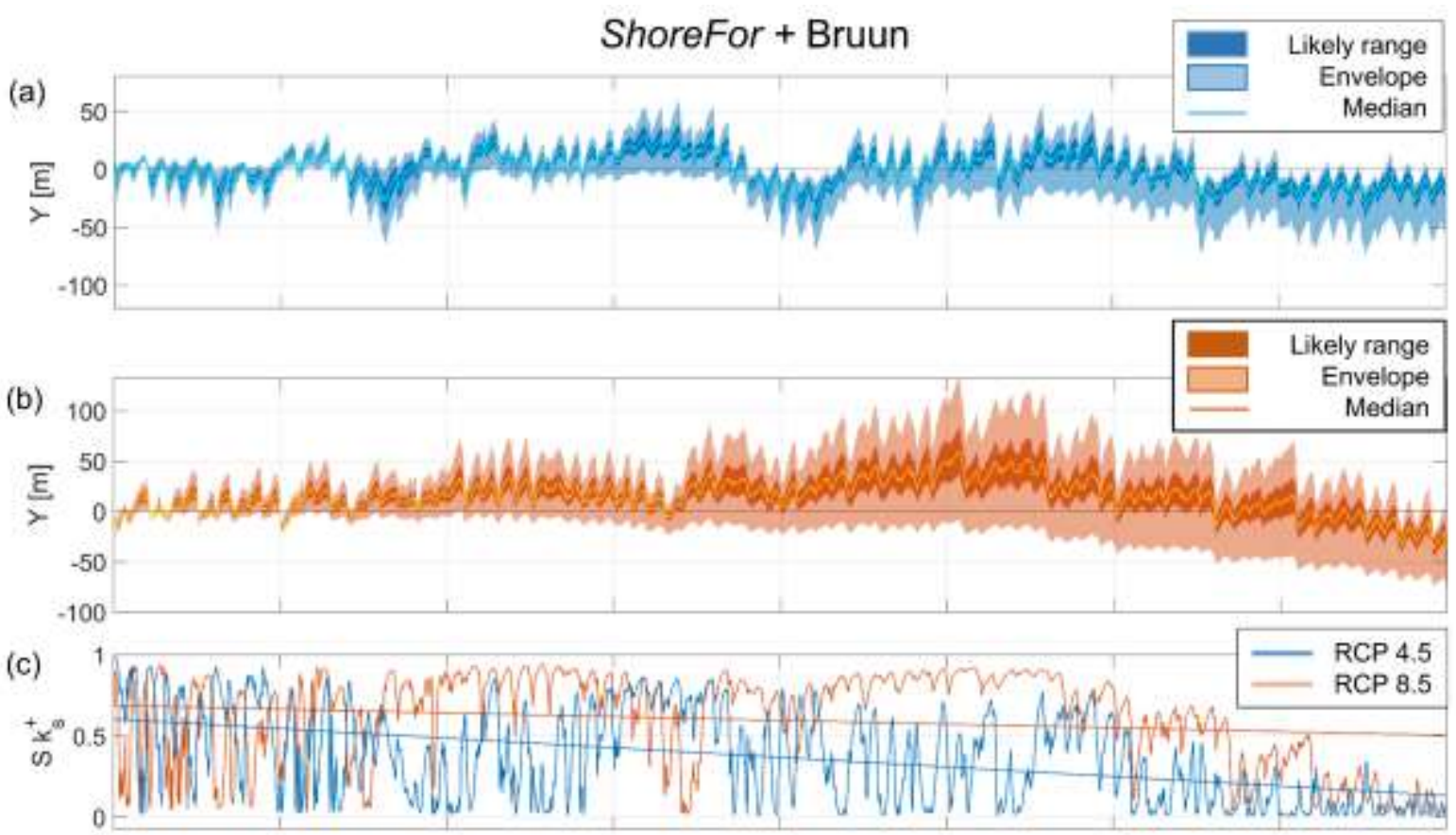

(d)
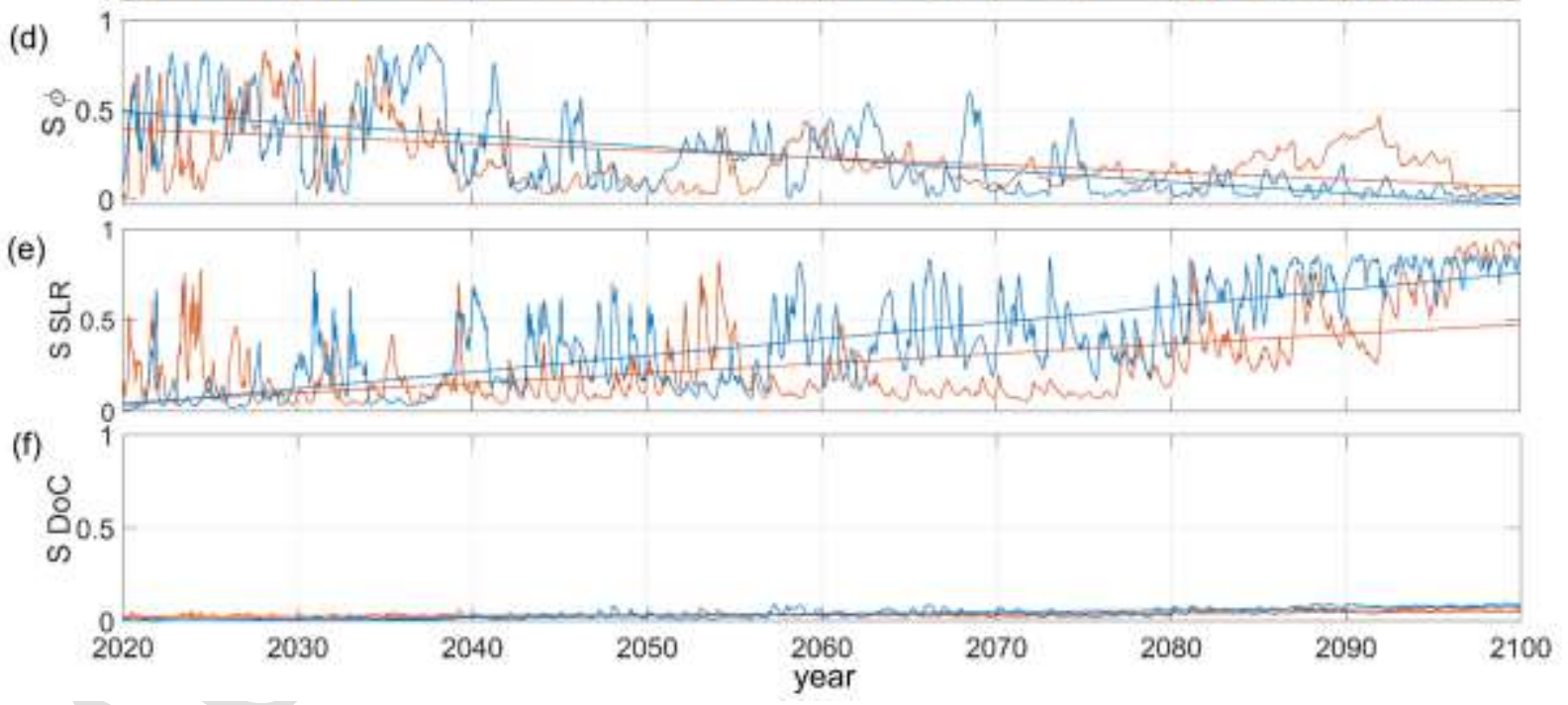

633

634

635

636

637

638

Figure 8 Global Sensitivity Analysis results over the period 2020-2100 using the ShoreFor model in the RCP4.5 (blue lines) and RCP8.5 (orange lines) scenarios. (a) RCP4.5 and (b) RCP8.5 Ensemble shoreline projections (shaded areas) over 2020-2100; First-order Sobol' index time series for (c) $k_{s}{ }^{+}$, (d) $\Phi$, (e) sea-level rise, and (f) depth of closure, with respective linear fit (solid straight lines). 


\section{Discussion}

\subsection{Sea-level rise} While observed shoreline erosion in Aquitaine is not yet attributed to SLR, sooner or later a SLRdriven signal will emerge from the current shoreline change variability, as sea levels are committed to rise by meters over the coming centuries (Anderson et al., 2015; Oppenheimer et al., 2019). Our results suggest that these times of emergence of a SLR-driven erosive trend could be visible during the $2^{\text {nd }}$ half of the $21^{\text {st }}$ century, possibly by 2070 . This is consistent with the fact that uncertainty $\left(17^{\text {th }}-83^{\text {th }}\right.$ percentiles) in future sea level grows from roughly $15 \mathrm{~cm}$ by the mid $21^{\text {st }}$ century to 30 $\mathrm{cm}(\mathrm{RCP} 4.5)$ and $50 \mathrm{~cm}(\mathrm{RCP} 8.5)$ in 2100. Yet, this result relies on our modelling assumptions, including the Bruun Rule and the Yates or ShoreFor models.

The GSA applications to four simulated scenarios indicate that uncertainties in the modelled 20202100 shoreline projections at Truc Vert are primarily caused by uncertainties in model free parameters between the present day and 2050. The effects SLR uncertainties always emerge as a significant contribution to the shoreline change uncertainties in the second half of the century. We also observed that the time evolution of $S_{i}$ s and the onset of SLR uncertainties effects are conditional to the RCP scenario (in agreement with Le Cozannet et al., 2019), the choice of shoreline model, and the variability of forcing wave climate.

The shoreline trajectory obtained in the deterministic high-end SLR scenario exceeds the envelope of probabilistic projections in the last simulated decade. Truc Vert beach is remote and backed by a high $(\sim 20 \mathrm{~m})$ and wide $(\sim 250 \mathrm{~m})$ dune system, so that shoreline retreat is not limited by nonerodible geological outcrops or coastal structure. While such large erosion does not threaten any human assets close to Truc Vert beach, such scenario, though unlikely, questions adaptation planning in other eroding urbanised coastal areas with limited accommodation space in southwest France. 
5.2 Shoreline models

While the SF and Y09 models are both based on the equilibrium beach concept, the respective model structures and parameters associate different physical interpretations and shoreline behaviours (Section 2.4.1). Therefore, the uncertainty associated with the choice of the equilibrium modelling approach cannot be measured by direct confrontation of the $S_{i}$ s obtained with the two models, but requires consideration of the different model responses to the forcing conditions.

The results obtained for the two disequilibrium approaches (Y09 and SF) show similar seasonal and interannual shoreline cycles, although with notably different amplitudes. Such behaviours are rooted in the different expressions of the equilibrium physics adopted in the two wave-driven models (i.e. the mechanism that would drive the shoreline to an equilibrium position under constant wave conditions). Vitousek et al. (2021) analytically show that the type of equilibrium condition is critical for the short- and long-term response of the shoreline model. On one hand, Y09's equilibrium condition depends on the current shoreline position, and is not influenced by storm events that occurred prior to a given time scale that is implicitly defined by the model calibration (see 'Appendix A' of Vitousek et al., 2021). On the other hand, SF's equilibrium state is determined by the (time varying) past wave conditions with an explicit 'beach memory' function, and evolves in time accordingly. This means that, in absence of other processes, the Y09 modelled shoreline oscillates persistently around the same position regardless of the temporal variability of wave energy. Instead, SF can only achieve such a stable mean shoreline trend when forced with a periodic long-term wave climate (Vitousek et al., 2021). Hence, in presence of longterm trends of wave energy, Y09 emphasizes the short-term shoreline erosion/accretion in order to re-establish the equilibrium shoreline position, while SF adapts to the wave climate pattern. The latter results in larger amplitudes of seasonal fluctuations and in attenuation of long-term fluctuations, compared to SF. 
687 The combined Y09 and Bruun models simulated shoreline ranges at 2100 are overall comparable to the ranges of the standalone Bruun Rule, indicating that in this scenario the net erosion modelled by 2100 is essentially driven by SLR. In fact, Y09 constrains the shoreline response to long-term wave climate shifts to a limited range (as described above) while the linearly added contribution of the Bruun model determines the shoreline trend. Instead, SF can produce wave-driven longterm shoreline trends that are combined with the Bruun retreat. This effect is observed in both RCP4.5 and 8.5 scenarios, where the decreasing wave energy trend (Figure $2 \mathrm{~d}, \mathrm{e}$ ) is translated by SF into shoreline accretion trends, resulting in less erosion than the Buun model alone (Table 3). Such properties of the two model behaviours highlight the different model sensitivities to longterm variability of the wave climate, which can have implications on the uncertainties in shoreline projections. Including the uncertainty of long-term wave climate variability in the ensemble projections would allow investigating the uncertainties related to the different behaviours of the shoreline models.

\subsection{Model free parameters}

Resolving process-based shoreline response to time-varying incident wave energy revealed that uncertainties in model parameters have the largest impact over the first simulated 30 years, regardless of the cross-shore shoreline model choice. Over this period, Y09 and SF uncertainties in response rate parameters $\left(k_{y}{ }^{+/}\right.$and $k_{s}{ }^{+}$, respectively) are responsible for most of the results uncertainties, which increases during low energy winters (on seasonal scale), and is particularly emphasized for SF in correspondence of extended low energy periods. This suggests that the assumption of a linear relationship between SF's response rate parameters $\left(k_{s}^{-}=r k_{s}{ }^{+}\right)$may not hold in the context of long-term simulations, as it might depend on the evolution of waves properties (Ibaceta et al., 2020). In fact, Ibaceta et al. (2020) found that, such relation is not 
necessarily linear, indicating that the value of $r$ may vary dynamically with changes in wave regimes. While the $S_{i}$ s of the remaining model parameters ( $\Phi$ for SF; $a_{1}$ and $a_{2}$ for Y09) show a definite seasonality, their variability on longer time scales is unclear. However, $\Phi$ 's $S_{i}$, which exhibit relatively high values (up to $90 \%$ ) at the beginning of the simulation, shows an overall decaying trend for both RCP scenarios applications. The $a_{1}$ and $a_{2}$ 's $S_{i}$ s remain weak, though not negligible, $(<20 \%)$ over all the simulated period.

The behaviour of the model free parameters' $S_{i}$ s highlights, once again, the importance of wave energy variability in determining the impact of the parameters uncertainties on shoreline projections. This was also observed in previous studies, which showed that changes in wave regime can alter the model parameters and the functional relations between them (Ibaceta et al., 2020; Splinter et al., 2017). As a perspective of future work, one way to reduce the effects of model free parameters' uncertainties on modelled shoreline may be to employ non-stationary parameters that can adjust to changes in wave-climate regimes (Ibaceta et al., 2020). The use of non-stationary parameters would also imply a dynamic value of the $r$ parameter, reducing uncertainties associated to the assumption of a linear relationship, between SF's response rate parameters. In addition, rearranging the Y09 parameters so that the new parameters have a similar order of magnitudes may increase the efficiency of model calibration, reducing model parameters uncertainties (Vitousek et al., 2021).

\subsection{The role of wave time series}

Our results indicate that the shoreline erosion is not only associated with large winter energy, but also depends on the trends of past winter wave energy and the internal variability of high-energy events within the season. For instance, in the RCP4.5 scenario the winters 2084-2085 and 20592060 show similar 3-month averaged $H_{s}{ }^{2} T_{p}$ peak $\left(164 \mathrm{~m}^{2} \mathrm{~s}\right.$ and $172 \mathrm{~m}^{2} \mathrm{~s}$, respectively), but they are 
733 preceded by several years of negative and positive winter energy trend, respectively (Figure 2b).

734 This results in the winter 2084-2085 producing a rapid landward shift of shoreline position

735 distribution, and the winter 2059-2060 driving more moderate annual changes while contributing

736 to a long-term erosive trend (Figure 5c,d). We also observe that the interannual patterns of

737 shoreline evolution are clearly correlated to those of winter wave energy. These behaviours

738 underline the critical role of high/low energy winters interannual cycles, as well as storms

739 sequencing, in wave-driven shoreline response, in line with previous studies (Dissanayake et al.,

740 2015; Besio et al., 2017; Dodet et al., 2019). In addition, the temporal variability of wave climate

741 (e.g. seasonal distribution of storm events) has been observed to affect the frequency (or 'mode')

742 of shoreline response (Splinter et al., 2017; Ibaceta et al., 2020).

743 Therefore, we further investigated the potential role of future waves uncertainties in shoreline

744 projections performing the GSA on an additional ensemble of 3000 simulations forcing the Y09

745 and SF models with 100 different wave time series. We generated 100 random synthetic wave

746 series using the method proposed by Davidson et al. (2017), which consists in building continuous

747 series of wave conditions by sampling 1-month portions from a reference dataset of existing wave

748 data (e.g. historic wave data) at a given location. The method generates synthetic wave time series

749 with random, though realistic, chronology of wave events, while maintaining the seasonal and

750 yearly character of the wave climate. However, this assumes a long-term stationarity of the

751 generated wave time series. We used the BW18 projections for the RCP8.5 scenario as reference

752 wave data. We individually applied the Davidson et al. (2017) method over 8 windows of 10 years

753 from 2020 to 2100 in order to preserve the long-term (>10 years) characteristics of the reference

754 time series while providing enough sampling reference data (Figure 9a). For instance, all the 
755 synthetic events from 2030 to 2040 were generated using monthly samples from the 2030-2040

756 reference dataset.

757 When using the latter approach to generate ensemble waves the SF model shows some limitations.

758 Therefore, here we exploit only the test results obtained with Y09. The results of the SF test

759 application and the aforementioned limitations are illustrated in Text S5 and Figure S4 of

760 Supporting Information. 
Yates + Bruun RCP 8.5 (ensemble waves)
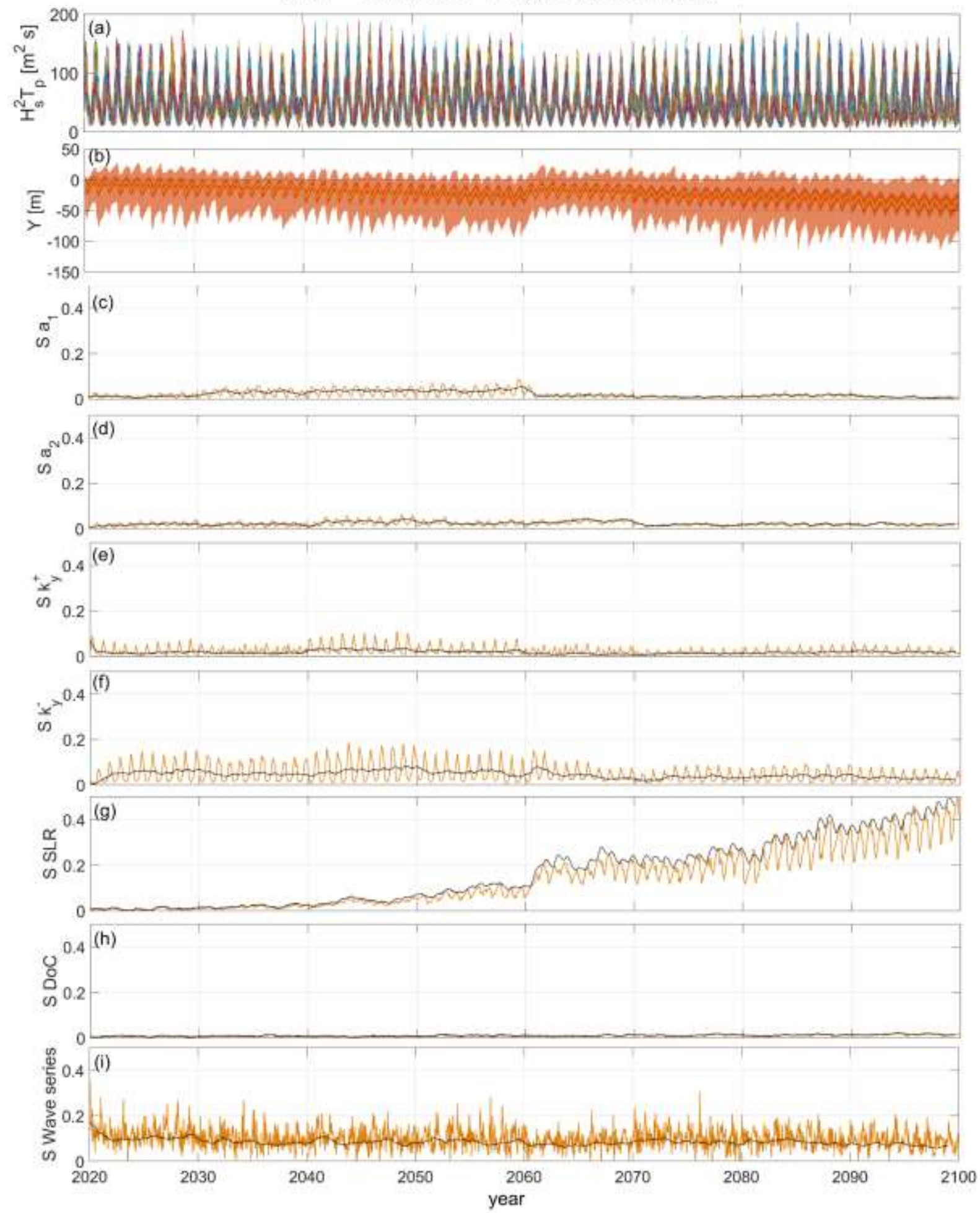

762 Figure 9 Ensemble of 3000 Yates simulations forced using (a) 3-month average energy $\left(H_{s}{ }^{2} T_{p}\right)$ of 763100 random wave time series from 2020 to 2100 generated with the Davidson et al. (2017) method based on the BW18 wave projections for the RCP8.5 scenario; (b) Ensemble shoreline projections 
over the analysed period (dark/light shaded areas indicate the likely/envelope range, i.e. variance (min-max), of shoreline position); First-order Sobol' index time series for (c) $k_{y}{ }^{+}$, (d) $k_{y}{ }^{-}$, (e) $a_{l}$, (f) $a_{2}$, (g) sea-level rise, (h) depth of closure, and (i) wave energy, with respective time series calculated on the 1-year running average of model results (black lines).

The GSA shows that introducing uncertainties in the temporal distribution of wave events (Figure 9a) has a large impact on the variance of model results (Figure 9b) and, in turn, on the relative contributions of the remaining uncertain input parameters (Figure 9c-h). In fact, accounting for uncertainty in wave events chronology (though in a simplistic way) increases the overall model variance throughout the entire simulated period (Figure $6 \mathrm{c}$ and Figure $9 \mathrm{~b}$ ), and associates a dominating $S i$ (up to 0.3 ) over the first half of the simulated period (Figure 9i). However, SLR's $S_{i}$ still emerges after 2060 and dominate shoreline projections uncertainties over the last two simulated decades. We also observe that the inclusion of wave chronology uncertainty attenuates the interannual variability of all $S_{i}$ s while preserving the seasonal and 10-year signals (Figure 9ch). This is a natural consequence of the method used to generate the wave series ensemble. In fact, the Davidson et al. (2017) method is designed to preserve the seasonal variability, while its application to fixed time windows of the reference time series constrains the ensemble members to maintain the 10-year variability. The black lines in Figure 9c-i show the time evolution of $S_{i}$ S obtained removing the seasonal signal from the model results with a 1-year running average. When the seasonal variability of the results is removed, the SLR's $S_{i}$ compensates the fluctuations of the model parameter's $S_{i}$ s, resulting in an increased trend.

The test application illustrated above suggests that including uncertainties in short-term wave chronology can significantly impact the uncertainties of shoreline projections and the relative contributions of the remaining uncertain input variables. Further, introducing uncertainties on long-term non-stationarity of wave conditions would overcome the SF limitations occurring in this 
specific application, and may unveil new implications of the different Y09 and SF equilibrium approaches in the context of probabilistic long-term shoreline projections.

\subsection{Assumptions and limitations}

Wave projections are affected by uncertainties owing to the choice of the Global Climate Model (Morim et al., 2020) and random variability of wave events. Although our results are based on deterministic BW18's wave projections, in the northeast Atlantic region the estimated future wave statistics have been observed to be mostly sensitive to the RCP scenario (Morim et al., 2020). Yet, the use of deterministic wave projections hides a potentially large impact of the uncertain waveclimate variability on both shoreline predictions uncertainty and behaviour of the shoreline models. In addition, accounting for uncertainties in wave projections may also increase the uncertainties in DoC, which were based on one deterministic wave time series in the present study. However, to the authors' knowledge there is no other dataset of continuous 2020-2100 wave projections, over the north Atlantic area, with a sufficient spatial resolution to resolve the site-specific regional scale processes. This underlines the need of continuous wave time series (obtained with different wave models of fine enough spatial resolution, different climate models, for different RCP scenarios), as well as tools allowing generating continuous realistic future wave time series, such as climate based stochastic wave emulators (Anderson et al., 2019; Cagigal et al., 2020).

In the current work, we assumed that MSL 2020-2100 projections are normally distributed. However, the MSL distribution may be skewed towards higher values due to additional uncertainty related to Antarctic ice-sheet melting in the RCP8.5 scenario. We simulated a deterministic RCP8.5 high-end SLR scenario to define a low-probability/high-impact scenario for projected shoreline erosion. Yet, our high-end SLR scenario is based on a particular combination of highend contributions to sea-level rise, which makes no consensus in the scientific community (Bamber 
812 et al., 2019; Edwards et al., 2021; Stammer et al., 2019). While this is not included in the GSA,

813 the use of a skewed probability distribution may lead to an earlier onset of SLR uncertainties in

814 shoreline projections.

815 The Bruun Rule, used in our application to estimate SLR-driven shoreline recession, builds on 816 several strong assumptions that reduce the applicability of this model to a limited range of beaches

817 (Cooper et al., 2020). As the Truc Vert is an uninterrupted natural cross-shore transport dominated 818 beach, with large sediment availability, most underlying assumption of the Bruun model are 819 satisfied. However, alternative models to address beach response to SLR, such as ShoreTrans 820 (McCarroll et al., 2020), can be implemented in this framework.

821 Coupling the Bruun Rule with Y09 and SF allows accounting for long-term effects of SLR while 822 resolving short-term shoreline response to the wave climate. The Y09 and SF models do not explicitly resolve sediment sediment exchange between the different beach compartments (e.g. 824 upper beach and dune), and may fail reproducing episodic shoreline changes such as short-term accretion following to dune erosion events. However, if such events occur during the model calibration period, as in our applications (i.e. winter 2013-2014), their influence on the bulk 827 shoreline response is partially accounted.

828 Here, we investigated the main effect of the uncertainties in input variables $\left(S_{i} \mathrm{~s}\right)$. While the 829 estimated $S_{i}$ of the DoC remains relatively low over the simulated period, in all simulated 830 scenarios, the interaction of DoC and SLR uncertainties (i.e. second-order Sobol' index) may have 831 a larger impact. However, estimating robust interaction terms would require a larger ensemble of 832 simulations (several tens of thousands). Furthermore, in order to rigorously conclude on the 833 negligible character of some uncertainties, GSA should be conducted within the factors' fixing 834 setting (i.e., investigating the 'total effect' of uncertain variables, Saltelli et al., 2008). In the 
835 presence of dependence among the inputs, more advanced GSA indices should be used for this

836 purpose. In particular, a method that employes the so-called Shapley effects has recently been

837 proposed and showed very promising results (Iooss \& Prieur, 2019). While the direct application

838 of this method requires computational cost of several order of magnitudes larger than the Sobol'

839 indices (see Iooss \& Prieur, 2019), Broto et al. (2020) successfully implemented a more

840 computationally efficient sampling-based method for GSA using Shapley indices. This may be an

841 interesting perceptive for future works.

\section{Conclusions}

843 We performed a Global Sensitivity Analysis on probabilistic 2020-2100 shoreline projections at 844 the cross-shore transport dominated Truc Vert beach in southwest France. Time varying first-order 845 Sobol' indices were calculated for sea-level rise, depth of closure, and model free parameters for 846 two different cross-shore shoreline models (Yates and ShoreFor) and two RCP scenarios (RCP4.5

847 and RCP8.5). We show that uncertainties in shoreline projections are initially driven by 848 uncertainties in model free parameters, with the effects of SLR uncertainties only emerging in the second half of the $21^{\text {st }}$ century. However, the relative effects of SLR and model parameters uncertainties on shoreline projections do not only depend on the shoreline modelling approach and RCP scenarios, but their time evolution is also related to the forcing wave-climate variability. We

852 also emphasize the importance of accounting for uncertainties related to the temporal distribution of wave energy, and therefore the need of ensembles of synthetic wave time series that account for the inherent variability of the wave climate. 


\section{Acknowledgments and Data}

This work is co-financed by the BRGM and Make Our Planet Great Again (MOPGA) national program (Grant 927923G) and the BRGM (French Geological Survey). BC funded by Agence Nationale de la Recherche (ANR) grant number ANR-17-CE01-0014. GLC and RT are supported by H2020 ERA4CS ECLISEA (Grant 690462).

This study includes the monitoring study site of Truc Vert labelled by the Service National d'Observation (SNO) Dynalit (https://www.dynalit.fr) with additional support from Observatoire Aquitaine de l'Univers (OASU) and Observatoire de la Côte Aquitaine (OCA). The authors thank the colleagues, including S. Bujan, S. Ferreira and V. Marieu involved in the topographic data; SONEL for past sea levels and vertical land motion data (https://www.sonel.org/-GPS-.html); and the Integrated Climate Data Center at the University of Hamburg (https://icdc.cen.unihamburg.de/en/ar5-slr.html) for SLR projections data.

The authors are grateful to the reviewers (G. Coco, S. Vitousek and Anonymous reviewer), Associated Editor and Editor for their constructive remarks, which greatly improved this article.

\section{Data availability statement}

All data used (wave, mean sea level and shoreline data) and produced (shoreline projections) in this work are available at https://data.mendeley.com/datasets/gnvkx44t63/draft?a=a32c56baf495-4652-9eda-964dea31cec6.

\section{Conflicts of interest}

The authors declare that there is no conflict of interest that could be perceived as prejudicing the impartiality of the research reported. 
878

879

880

881

882

883

884

885

886

887

888

889

890

891

892

893

894

895

896

897

898

899

\section{References}

Allenbach, K., Garonna, I., Herold, C., Monioudi, I., Giuliani, G., Lehmann, A., \& Velegrakis, A. F. (2015). Black Sea beaches vulnerability to sea level rise. Environmental Science \& Policy, 46, 95-109. doi:10.1016/j.envsci.2014.07.014

Anderson, T. R., Fletcher, C. H., Barbee, M. M., Frazer, L. N., \& Romine, B. M. (2015). Doubling of coastal erosion under rising sea level by mid-century in Hawaii. Natural Hazards, 78(1), 75103. https://doi.org/10.1007/s11069-015-1698-6

Anderson, D., Rueda, A., Cagigal, L., Antolinéz, J.A.A., Mendez, F.J., \& Ruggiero, P. (2019).Time-varying emulator for short and long-term analysis of coastal flood hazard potential. J. Geophys. Res. Ocean., 124(12), 9209-9234. doi.org/10.1029/2019JC015312

Angnuureng, A.B., Almar, R., Senechal, N., Castelle, B., Addo, K.A., Marieu, V., \& Ranasinghe, R., (2017). Shoreline resilience to individual storms and storm clusters on a meso-macrotidal barred beach. Geomorphology. 290, 265-276.doi:10.1016/j.geomorph.2017.04.007

Antolínez, J.A.A., Méndez, F.J., Anderson, D., Ruggiero, P., \& Kaminsky, G.M. (2019). Predicting climate driven coastlines with a simple and efficient multi-scale model. J. of Geophys.Res. Earth Surface 124, 1596-1624. https://doi.org/10.1029/2018JF004790

Athanasiou, P., van Dongeren, A., Giardino, A., Vousdoukas, M.I., Ranasinghe, R., \& Kwadijk, J. (2020). Uncertainties in projections of sandy beach erosion due to sea level rise: an analysis at the European scale. Sci Rep. 10, 11895. doi.org/10.1038/s41598-020-68576-0

Bamber, J.L., Oppenheimer, M., Kopp, R.E., Aspinall, W.P., \& Cooke, R.M. 2019. Ice sheet contributions to future sea-level rise from structured expert judgment. Proceedings of the National Academy of Sciences, 116(23), 11195-11200. doi.org/10.1073/pnas.1817205116 
900 Besio, G., Briganti, R., Romano, A., Mentaschi, L., \& De Girolamo, P. (2017). Time clustering of 901 wave storms in the Mediterranean Sea. Nat. Hazards Earth Syst. Sci. 17, 505-514. 902 doi.org/10.5194/nhess-17-505-2017

903 Bertsimas, D., \& Tsitsiklis, J. (1993). Simulated annealing. Statistical Science 8(1): 10-15. 904 https://doi.org/10.1214/ss/1177011077

905 Bricheno, L., \& Wolf, J. (2018). Future Wave Conditions of Europe, in Response to High-End 906 Climate Change Scenarios. J. of Geophys. Res. Oceans 123(12), 8762-8791. $907 \quad$ doi.org/10.1029/2018JC013866

908 Broto, B., Bachoc, F., \& Depecker, M. (2020). Variance reduction for estimation of Shapley effects 909 and adaptation to unknown input distribution. SIAM/ASA Int. J. on Uncertainty Quantification, 910 8(2), 693-716. https://doi.org/10.1137/18M1234631

911 Bruun, P. (1962). Sea-level rise as a cause of shore erosion. J. of the Waterways and Harbors 912 Division, 88 (1), 117-132.

913 Bruun, P. (1988). The Bruun Rule of Erosion by Sea-Level Rise: A Discussion on Large-Scale 914 Two- and Three-Dimensional Usages. J. of Coastal Res., 4 (4), 627-648. JSTOR, $915 \quad$ www.jstor.org/stable/4297466

916 Cagigal, L., Rueda, A., Anderson, D., Ruggiero, P., Marrifield, M.A., Montaño, J., Coco, G., et al. 917 (2020). A multivariate, stochastic, climate-based wave emulator for shoreline change modelling. 918 Ocean Modelling. 154, 101695. doi.org/10.1016/j.ocemod.2020.101695

919 Casas-Prat, M., McInnes, K. L., Hemer, M. A., \& Sierra, J. P. (2016). Future wave-driven coastal 920 along the Catalan coast (NW Mediterranean). Regional Environmental Change 16(6), 1739-1750. $921 \quad \underline{\text { doi: } 10.1007 / \mathrm{s} 10113-015-0923-\mathrm{X}}$ 
922 Castelle, B., Bujan, S., Marieu, V., \& Ferreira, S. (2020). 16 years of topographic surveys of rip923 channelled high-energy meso-macrotidal sandy beach. Sci. Dat., 7, 410. doi.org/10.1038/s41597-

$924 \quad \underline{020-00750-5}$

925 Castelle, B., Dodet, G., Masselink, \& G., Scott, T. (2017). A new climate index controlling winter 926 wave activity along the Atlantic coast of Europe: The West Europe Pressure Anomaly. Geophys. 927 Res. Lett., 44 (3), 1384-1392. doi :10.1002/2016GL072379

928 Castelle, B., Dodet, G., Masselink, G., \& Scott, T. (2018a). Increased winter-mean wave height, 929 variability and periodicity in the North-East Atlantic over 1949-2017. Geophys. Res. Lett., 45(8), $930 \quad 3586-3596$. doi:10.1002/2017GL076884

931 Castelle, B., Guillot, B., Marieu, V., Chaumillon, E., Hanquez, V., Bujan, S., \& Poppeschi, C. 932 (2018b). Spatial and temporal patterns of shoreline change of a 280-km high-energy disrupted 933 $934 \quad$ doi:10.1016/j.ecss.2017.11.005

935 Castelle, B., Marieu, V., Bujan, S., Ferreira, S., Parisot, J., Capo, S., Sénécha, N., et al. (2014). 936 Equilibrium shoreline modelling of high energy meso-macrotidal multiple barred beach. Marine 937 Geology, 347: 85-94. doi.org/10.1016/j.margeo.2013.11.003

938 Castelle, B., Marieu, V., Bujan, S., Splinter, K. D., Robinet, A., Sénéchal, N., \& Ferreira, S. 939 (2015). Impact of the winter 2013-2014 series of severe Western Europe storms on a double940 barred sandy coast: beach and dune erosion and megacusp embayments. Geomorphology, 238, $941 \quad$ 135-148. doi:10.1016/j.geomorph.2015.03.006

942 Charles E., Idier, D., Delecluse, P., Déqué, M., \& Le Cozannet, G. (2012). Climate change impact 943 on waves in the Bay of Biscay, France. Ocean Dynamics. doi.org/10.1007/s10236-012-0534-8 
944 Church, J.A., Clark, P.U., Cazenave, A., Gregory, J.M., Jevrejeva, S., Levermann, A., Merrifield, 945 M.A., et al., (2013). Sea Level Change. In Climate Change 2013: The Physical Science Basis; 946 Contribution of Working Group I to the Fifth Assessment Report of the Intergovernmental Panel 947 on Climate Change ed.; Cambridge University Press: Cambridge, UK, 2013.

948 Coco G., Senechal N., Rejas A., Bryan K.R., Capo S., Parisot J.P., Brown, J.A., et al. (2014). 949 Beach response to a sequence of extreme storms. Geomorphology 204, 493-501. $950 \quad$ doi:10.1016/j.geomorph.2013.08.028

951 Cooper, J.A.G., Masselink, G., Coco, G., Short, A.D., Castelle, B., Rogers, K., Anthony, E., et al. 952 (2020). Sandy beaches can survive sea-level rise. Nat. Clim. Chang. 10, 993-995. 953 doi.org/10.1038/s41558-020-00934-2

954 Cooper, J. A. G., \& Pilkey, O. H. (2004). Sea-level rise and shoreline retreat: time to abandon the 955 Bruun Rule. Global Planet Change, 43(3-4), 157-171. doi:10.1016/j.gloplacha.2004.07.001

956 D’Anna, M., Castelle, B., Idier, D., Le Cozannet, G., Rohmer, J. \& Robinet, A. (2020). Impact of 957 model free parameters and sea-level rise uncertainties on 20-years shoreline hindcast: the case of 958 Truc Vert beach (SW France). Earth Surf. Proc. and Landf. 45(8), 1895-1907. 959 doi:10.1002/esp.4854

960 Davidson, M. A., Splinter, K. D., \& Turner, I. L. (2013). A simple equilibrium model for predicting 961 shoreline change. Coast. Eng. 73, 191-202. doi:10.1016/j.coastaleng.2012.11.002

962 Davidson, M. A., Turner, I. L, Splinter, K. D., \& Harley, M.D. (2017). Annual prediction of 963 shoreline erosion and subsequent recovery. Coastal Engineering 130, 14-25. 964 doi.org/10.1016/j.coastaleng.2017.09.008 
965 Dissanayake, P., Brown, J., Wisse, P., \& Karunarathna, H. (2015). Comparison of storm cluster vs 966 isolated event impacts on beach/dune morphodynamics. Estuarine, Coastal and Shelf Science. 164, 967 301-312. https://doi.org/10.1016/j.ecss.2015.07.040

968 Dodet, G., Castelle, B., Masselink, G., Scott, T., Davidson, M., Floc'h, F., Jackson, D., et al. 969 (2019). Beach recovery from extreme storm activity during the 2013-14 winter along the Atlantic 970 coast of Europe. Earth Surface Processes and Landforms, 44(1), 393-401.doi:10.1002/esp.4500 971 Edwards, T.L., Brandon, M.A., Durand, G., Edwards, N.R., Golledge, N.R., Holden, P.B., Nias, 972 I.J. et al. (2019). Revisiting Antarctic ice loss due to marine ice-cliff instability. Nature 566, 58973 64. doi.org/10.1038/s41586-019-0901-4

974 Edwards, T.L., Nowicki, S., Marzeion, B., Hock, R., Goelzer, H., Seroussi, H., Jourdain, N.C. et 975 al. (2021). Projected land ice contributions to 21 st century sea level rise. Nature (in Press).

976 Frederikse, T., Landerer, F., Caron, L., Adhikari, S., Parkes, D., Humphrey, V.W., Dangendorf, 977 S., et al. (2020). The causes of sea-level rise since 1900. Nature, 584(7821), 393-397. $978 \quad \underline{10.1038 / \mathrm{s} 41586-020-2591-3}$

979 Ghermandi, A., \& Nunes P.A.L.D. (2013). A global map of coastal recreation values: Results from 980 a spatially explicit meta-analysis. Ecological Economics 86, 1-15. $981 \quad$ doi:10.1016/j.ecolecon.2012.11.006

982 Grinsted, A., Jevrejeva, S., Riva, R.E.M., \& Dahl-Jensen, D. (2015). Sea level rise projections for 983 northern Europe under RCP8.5. Clim Res 64, 15-23. https://doi.org/10.3354/cr01309

984 Hallermeier, R.J. (1978). Uses for a calculated limit depth to beach erosion. In Proceedings of the 985 16th Coastal Engineering Conference. ASCE: New York; 1493-1512. 
Hazeleger, W., Wang, X., Severijns, C., stefãnescu, S., Bintanja, R., Sterl, A., Wyser, K., et al. (2012). EC-Earth v2. 2: Description and validation of a new seamless Earth system prediction model. Climate Dynamics 39(11), 2611-2629. https://doi.org/10.1007/s00382-011-1228-5

Hinkel, J., Church, J.A., Gregory, J.M., Lambert, E., Le Cozannet, G., Lowe, J., MCInnes, K.L., et al. (2019). Meeting user needs for sea level rise information: A decision analysis perspective.

\section{Earth's Future, 7, 320-337. https://doi.org/10.1029/2018EF001071}

Hunter, J. R., Church, J. A., White, N. J., \& Zhang X. (2013). Towards a global regionally varying allowance for sea-level rise. Ocean Engineering 71, 17-27. doi:10.1016/j.oceaneng.2012.12.041

Ibaceta, R., Splinter, K.D., Harley, M.D., \& Turner, I.L. (2020). Enhanced Coastal Shoreline Modeling Using an Ensemble Kalman Filter to include Nonstationarity in Future Wave Climates. Geophys. Res. Lett. 47(22). doi.org/10.1029/2020GL090724

Iooss, B., \& Prieur, C. (2019). Shapley effects for sensitivity analysis with correlated inputs: comparisons with Sobol' indices, numerical estimation and applications. Int. J. for Uncertainty Quantification 9(5), 493-514. 10.1615/Int.J.UncertaintyQuantification.2019028372

Jackson, L.P., \& Jevrejeva, S. (2016). A probabilistic approach to 21st century regional sea-level projections using RCP and High-end scenarios. Global and Planetary Change 146, 179-189. doi.org/10.1016/j.gloplacha.2016.10.006

Jevrejeva, S., Frederikse, T., Kopp, R. E., Le Cozannet, G., Jackson, L. P., \& van de Wal, R. S. W. (2019). Probabilistic Sea Level Projections at the Coast by 2100. Surveys in Geophysics, 1-24. $\underline{\text { doi:10.1007/s10712-019-09550-y }}$

Klingebiel, \& Legigan (1992). Carte Géologique et structure du Bassin de la Leyre. Bull. Inst. Géol. Bassin Aquitaine, Bordeaux, 1992, n51-52, p7-20. 
1008 Kopp, R.E., Horton, R.M., Little, C.M., Mitrovica, J.X., Oppenheimer, M., Rasmussen, D.J., 1009 Strauss, B.H., et al. (2014). Probabilistic 21st and 22nd century sea-level projections at a global 1010 network of tide-gauge sites. Earth's Future, 2(8), 383-406. doi.org/10.1002/2014EF000239

1011 Kroon, A., de Schipper, M.A., van Gelder, P., \& Arninkhof, S.G.J. (2020). Ranking uncertainty:

1012 Wave climate variability versus model uncertainty in probabilistic assessment of coastline change. 1013 Coastal Engineering, 158, 103673. doi:10.1016/j.coastaleng.2020.103673

1014 Laporte-Fauret, Q., Marieu, V., Castelle, B., Michalet, R., Bujan, S., \& Rosebery, D. (2019). Low1015 Cost UAV for High-Resolution and Large-Scale Coastal Dune Change Monitoring Using 1016 Photogrammetry. J.l of Marine Science and Engineering 7(3), 63. doi:10.3390/jmse7030063

1017 Larson, M., Hogan, L. X., \& Hanson, H. (2010). Direct formula to compute wave height and angle 1018 at incipient breaking. J. of Waterway Port, Coastal and Ocean Engineering, 136(2), 119-122. 1019 doi:10.1061/(ASCE)WW.1943-5460.0000030

1020 Le Cozannet, G., Castelle, B., Bulteau, T., Ranasinghe, R., Wöppelmann, G., Rohmer, J., Bernon, 1021 N., et al. (2019). Quantifying uncertainties of sandy shoreline change projections as sea level rises. 1022 Sci Rep 42(9). 10.1038/s41598-018-37017-4

1023 Le Cozannet, G., Oliveros, C., Castelle, B., Garcin, M., Idier, D., Pedreros, R., \& Rohmer, J. 1024 (2016). Uncertainties in sandy shorelines evolution under the Bruun rule assumption. Frontiers of 1025 Marine Science 3, 49. doi:10.3389/fmars.2016.00049

1026 Lemos, C., Floc’h, F., Yates, M., Le Dantec, N., Marieu, V., Hamon, K., \& Delacourt, C. (2018).

1027 Equilibrium modelling of the beach profile on a macrotidal embayed low tide terrace beach. Ocean 1028 Dynamics, 68(9), 1207-1220. doi:10.1007/s10236-018-1185-1 
1029 Li, C., \& Mahadevan, S. (2016). An efficient modularized sample-based method to estimate the

1030 first-order Sobol' index. Reliability Engineering and System Safety, 153, 110-121.

$1031 \quad$ doi:10.1016/j.ress.2016.04.012

1032 Losada, I.J., Toimil, A., Muñoz, A., Garcia-Fletcher, A.P., \& Diaz-Simal, P. (2019). A planning

1033 strategy for the adaptation of coastal areas to climate change: The Spanish case. Ocean and Coastal

1034 Management, 182, 104983. doi:10.1016/j.ocecoaman.2019.104983

1035 Luijendijk, A., Hagenaars, G., Ranasinghe, R., Baart, F., Donchyts, G., \& Aarninkhof, S. (2018).

1036 The State of the World's Beaches. Sci Rep 8, 6641. doi:10.1038/s41598-018-24630-6

1037 Masselink, G., Castelle, B., Scott, T., Dodet, G., Suanez, S., Jackson, D., \& Floc'h, F. (2016).

1038 Extreme wave activity during 2013/2014 winter and morphological impacts along the Atlantic

1039 coast of Europe. Geophysical Research Letters 43(5), 2135-2143. doi:10.1002/2015GL067492

1040 McCarroll, R.J., Masselink, G., Valiente, N.G., Scott, T., Wiggins, M., Kirby, J.A., \& Davidson

1041 M. (2020). A novel rules-based shoreface translation model for predicting future coastal change:

1042 ShoreTrans. (Under Review). https://doi.org/10.31223/osf.io/y4kmv

1043 Merkens, J.L., Reimann, L., Hinkel, J., \& Athanasios, T.V. (2016). Gridded population projections

1044 for the coastal zone under the Shared Socioeconomic Pathways. Global and Planetary Change

1045 145, 57-66. https://doi.org/10.1016/j.gloplacha.2016.08.009

1046 Michaud, H., Pasquet, A., Leckler, F., Baraille, R., Dalphinet, A., \& Aouf, L. (2016).

1047 Improvements of the new French coastal wave forecasting system and application to a wave-

1048 current interaction study. SHOM \& Meteo France. doi:10.13140/RG.2.2.13218.02243

1049 Montaño, J., Coco, G., Antolínez, J. A.A., Beuzen, T., Bryan, K. R., Cagigal, L., Castelle, B., et

1050 al. (2020). Blind testing of shoreline evolution models. Sci Rep 10(1), 2137.

1051 doi.org/10.1038/s41598-020-59018-y 
1052 Morim, J., Hemer, M., Wang, X.L., Cartwright, N., Trenham, C., Semedo, A., Young, I., et al. 1053 (2019). Robustness and uncertainties in global multivariate wind-wave climate projections. Nature 1054 Climate Change 9, 711-718. doi:10.1038/s41558-019-0542-5

1055 Morim, J., Trenham, C., Hemer, M., Wang, X.L., Mori, N., Casas-Prat, M., Semedo, A., et al. 1056 (2020). A global ensemble of ocean wave climate projections from CMIP5-driven models. Sci 1057 Data 7, 105. https://doi.org/10.1038/s41597-020-0446-2

1058 Nash, J.E., \& Sutcliffe, J.V. (1970). River flow forecasting through conceptual models part I-a 1059 discussion of principles. J. Hydrol., 10, 282-290. 10.1016/0022-1694(70)90255-6

1060 Neuman, B., Athanasios, T.V., Zimmermann, J., \& Nicholls, R.J. (2015). Future Coastal 1061 Population Growth and Exposure to Sea-Level Rise and Coastal Flooding - A Global Assessment. 1062 Plos One, 10(6), e0131375. doi.org/10.1371/journal.pone.0131375

1063 Nicholls, R.J. (1998). Assessing erosion of sandy beaches due to sea-level rise. Geological Society, 1064 London, Engineering Geology Special Publications 15(1), 71-76. 1065 doi:10.1144/GSL.ENG.1998.015.01.08

1066 Oppenheimer, M.B.C., Glavovic, J., Hinkel, R., van de Wal, A.K., Magnan, A., et al. (2019). Sea 1067 Level Rise and Implications for Low-Lying Islands, Coasts and Communities. In: IPCC Special 1068 Report on the Ocean and Cryosphere in a Changing Climate [Pörtner, H.-O., Roberts, D.C., 1069 Masson-Delmotte, V., Zhai, P., Tignor, M., Poloczanska, E., Mintenbeck, K., Alegría, A., Nicolai, 1070 M., Okem, A., Petzold, J., Rama, B., Weyer, N.M. (eds.)]

1071 Parisot, J. P, Capo, S., Castelle, B., Bujan S., Moreau, J. M., Gervais, M., Réjas, A., et al. (2009). 1072 Treatment of topographic and bathymetric data acquired at the Truc-Vert Beach (SW France) 1073 during the ECORS field experiment [Special issue]. J. of Coastal Research 56, Proceedings of the 
1074 10th International Coastal Symposium ICS 2009, Vol. II, 1786-1790. $1075 \quad$ www.jstor.org/stable/25738097

1076 Perez, J., Menendez, M., Camus, P., Mendez, F.J. \& Losada, I.J. (2015). Statistical multi-model 1077 climate projections of surface ocean waves in Europe. Ocean Modelling, 96, 161-170. $1078 \quad$ doi.org/10.1016/j.ocemod.2015.06.001

1079 Poumadère, M., Bertoldo, R., Idier, D., Mallet, C., Oliveros, C., \& Robin, M. (2015). Coastal 1080 vulnerabilities under the deliberation of stakeholders: The case of two French sandy beaches. 1081 Ocean \& Coastal Management 105, 166-176. doi.org/10.1016/j.ocecoaman.2014.12.024

1082 Ranasinghe, R. (2016). Assessing climate change impacts on open sandy coasts: A review. Earth 1083 Sci Rev 160, 320-332. doi:10.1016/j.earscirev.2016.07.011

1084 Ranasinghe, R. (2020). On the need for a new generation of coastal change models for the 21st 1085 century. Sci Rep 10, 2010. doi.org/10.1038/s41598-020-58376-x

1086 Ranasinghe, R., Callaghan, D., \& Stive, M.J.F. (2012). Estimating coastal recession due to sea 1087 level rise: beyond the Bruun rule. Climatic Change 110, 561-574. doi:10.1007/s10584-011-0107$1088 \underline{8}$

1089 Reguero, B.G., Losada, I.J., \& Mendez, F.J. (2019). A recent increase in global wave power as a 1090 consequence of oceanic warming. Nature Communications 10, 205. 1091 https://doi.org/10.1038/s41467-018-08066-0

1092 Robin, N., Billy, J., Castelle, B., Hesp, P., Nicolae Lerma, A., Laporte-Fauret, Q., Marieu, V., et 1093 al. (2021). 150 years of foredune initiation and evolution driven by human and natural processes. 1094 Geomorphology, 374, 107516. https://doi.org/10.1016/j.geomorph.2020.107516

1095 Robinet, A., Castelle, B., Idier, D., Le Cozannet, G., Déqué, M., \& Charles, E. (2016). Statistical 1096 modeling of interannual shoreline change driven by North Atlantic climate variability spanning 
1097 2000-2014 in the Bay of Biscay. Geo-Marine Letters, 36(6), 479-490. doi:10.1007/s00367-016-

$1098 \quad \underline{0460-8}$

1099 Robinet, A., Idier, D., Castelle, B., \& Marieu, V. (2018). A reduced-complexity shoreline change 1100 model combining longshore and cross-shore processes: The LX-Shore model. Environmental 1101 Modelling and Software 109, 1-16. doi:10.1016/j.envsoft.2018.08.010

1102 Rohmer, J., \& Le Cozannet, G. (2019). Dominance of the mean sea level in high-percentile sea

1103 levels time evolution with respect to large-scale climate variability: a Bayesian statistical

1104 approach. Environmental Research Letters, 14(1). doi:10.1088/1748-9326/aaf0cd

1105 Saltelli, A., Ratto, M., Andres T., Campolongo, F., Cariboni, J., Gatelli, D., Saisana, M., et al.

1106 (2008). Global Sensitivity Analysis: The premier. The Atrium, Southern Gate, Chichester,West

1107 Sussex PO19 8SQ, England. Jhon Wiley \& Sons Ltd.

1108 Santamaría-Gómez, A., Gravelle, M., Dangendorf, S., Marcos, M., Spada, G., \& Wöppelmann, G.

1109 (2017). Uncertainty of the 20th century sea-level rise due to vertical land motion errors. Earth and 1110 Planetary Science Letters. 473, 24-32. doi:10.1016/j.eps1.2017.05.038

1111 Sobol', I.M. (2001). Global sensitivity indices for nonlinear mathematical models and their Monte

1112 Carlo estimates. Mathematics and Computers in Simulation 55(1-3), 271-280. doi:10.1016/S0378-

$1113 \quad \underline{4754(00) 00270-6}$

1114 Splinter, K., Turner, I.L., \& Davidson, M.A. (2013). How much data is enough? The importance

1115 of morphological sampling interval and duration for calibration of empirical shoreline models.

1116 Coastal Engineering, 77, 14-27. doi:10.1016/j.coastaleng.2013.02.009

1117 Splinter, K., Turner, I.L., Davidson, M.A., Bernard, P., Castelle, B., \& Oltman-Shay, J. (2014a).

1118 A generalized equilibrium model for predicting daily to interannual shoreline response. $J$. of

1119 Geophysical Research Earth Surface 119(9), 1936-1958. doi:10.1002/2014JF003106 
1120 Splinter, K., Carley, J.T., Golshani, A., \& Tomlinson, R. (2014b). A relationship to describe the

1121 cumulative impact of storm clusters on beach erosion. Coastal Engineering. 83, 49-55.

1122 doi.org/10.1016/j.coastaleng.2013.10.001

1123 Splinter, K., Turner, I. L., Reinhardt, M., \& Ruessink, G. (2017). Rapid adjustment of shoreline

1124 behaviour to changing seasonality of storms: observations and modelling at an open-coast beach.

1125 Earth Surface Processes and Landforms 42(8), 1186-1194. doi:10.1002/esp.4088

1126 Slangen, A.B.A., Carson, M., Katsman, C.A., van de Wal, R.S.W., Kohl, A., Vermeersen, L.L.A.,

1127 \& Stammer, D. (2014). Projecting twenty-first century regional sea-level changes. Climatic

1128 Change 124, 317-332. doi.org/10.1007/s10584-014-1080-9

1129 Stammer, D., Van de Wal, R.S.W., Nicholls, R.J., Church, J.A., Le Cozannet, G., Lowe, J.A.,

1130 Horton, B.P., et al. (2019). Framework for high-end estimates of sea level rise for stakeholder

1131 applications. Earth's Future, 7(8), 923-938. doi:10.1029/2019EF001163

1132 Taylor, K.E., Stouffer, R.J., \& Meehl G.A. (2012). An Overview of CMIP5 and the experiment

1133 design. Bull. Amer. Meteor. Soc., 93, 485-498. doi:10.1175/BAMS-D-11-00094.1

1134 Thiéblemont, R., Le Cozannet, G., Rohmer, J., Toimil, A., Alvarez-Cuesta, M., and Losada, I.J.

1135 (in review, 2021). Deep uncertainties in shoreline change projections: an extra-probabilistic

1136 approach applied to sandy beaches. Nat. Hazards Earth Syst. Sci Discuss. [preprint].

1137 doi.org/10.5194/nhess-2020-412/

1138 Thiéblemont, R., Le Cozannet, G., Toimil, A., Meyssignac, B., \& Losada, I.J. (2019). Likely and

1139 High-End Impacts of Regional Sea-Level Rise on the Shoreline Change of European Sandy Coasts

1140 Under a High Greenhouse Gas Emissions Scenario. Water, 11, 2607. doi:10.3390/w11122607 
1141 Toimil, A., Camus, P., Losada, I.J., Le Cozannet, G., Nicholls, R., Idier, D., \& Maspataud, A.

1142 (2020). Climate Change Driven coastal erosion modelling in temperate sandy beaches methods

1143 and uncertainty treatment. Earth Science Reviews. 202, 103110. doi.j.earscirev.2020.103110

1144 Toimil, A., Diaz-Simal, P., Losada, I.J., \& Camus, P. (2018). Estimating the risk of loss of beach

1145 recreation value under climate change. Tourism Management, 68, 387-400.

1146 doi:j.tourman.2018.03.024

1147 Toimil, A., Losada, I. J., Camus, P., \& Diaz-Simal, P. (2017). Managing coastal erosion under

1148 climate change at regional scale. Coastal Engineering, 128, 106-122. doi:j.coastaleng.2017.08.004

1149 Tolman, H. (2009). User manual and system documentation of WAVEWATCH III-version 3.14

1150 (Tech. rep.): NOAA / NWS / NCEP / MMAB Technical Note-276.

1151 Vitousek, S., Barnard, P. L., Limber, P., Erikson, L., \& Cole, B. (2017). A model integrating

1152 longshore and cross-shore processes for predicting long-term shoreline response to climate change.

1153 J. of Geophys.l Res. Earth surface, 122 (4), 782-806. doi:10.1002/2016JF004065

1154 Vitousek, S., Cagigal, L., Montaño, J., Rueda, A.C., Mendez, F.J., Coco, G., \& Barnard, P. (2021).

1155 The application of ensemble wave forcing to quantify uncertainty of shoreline change predictions.

1156 J. of Geophys. Res. Earth Surface, (in Press). doi.org/10.1029/2019JF005506

1157 Vousdoukas, M.I., Ranasinghe, R., Mentaschi, L., Plomaritis, T.A., Athanasiou, P., Luijendijk, A.

1158 \& Feyen, L. (2020). Sandy coastlines under threat of erosion. Nat. Clim. Chang. 10, $260-263$.

1159 doi.org/10.1038/s41558-020-0697-0

1160 Wainwright, D.J., Ranasinghe, R., Callaghan, D.P., Woodroffe, C.D., Jongejan, R., Dougherty,

1161 A.J., Rogers, K., et al. (2015). Moving from deterministic towards probabilistic coastal hazard and

1162 risk assessment: development of a modelling framework and application to Narrabeen Beach, New

1163 South Wales, Australia. Coastal Engineering, 96, 92-99. doi:10.1016/j.coastaleng.2014.11.009 
1164 Wong, P.P., Losada, I.J., Gattuso, J.P., Hinkel, J., Khattabi, A., McInnes, K.L., Saito, Y. et al. 1165 (2014). Coastal systems and low-lying areas. In: Climate Change 2014: Impacts,Adaptation, and 1166 Vulnerability. Part A: Global and Sectoral Aspects. Contribution of working group II to the Fifth 1167 Assessment Report of the Intergovernmental Panel on Climate Change. Cambridge, United 1168 Kingdom and New York, NY, USA. Cambridge University Press, 361-409.

1169 Wright, L.D., \& Short, A.D. (1984). Morphodynamic variability of surf zones and beaches: a 1170 synthesis. Marine Geology, 56(1-4), 93-118. doi:10.1016/0025-3227(84)90008-2

1171 Wolinsky M.A., \& Murray, A.B. (2009). A unifying framework for shoreline migration: 2. 1172 Application to wave-dominated coasts. J. Geophys. Res. 114, F01009, doi:10.1029/2007JF000856

1173 Yates, M.L., Guza, R.T., \& O’Reilly, W.C. (2009). Equilibrium shoreline response: Observations 1174 and modeling. J. of Geophysical Research Oceans 114(C9), C09014. doi:/10.1029/2009JC005359 